\title{
Hearing Screening for Residents in Long-Term Care Homes Who Live with Dementia: A Scoping Review
}

Fiona Höbler ${ }^{\mathrm{a}, \mathrm{b}}$, Katherine S. McGilton ${ }^{\mathrm{a}, \mathrm{b}, \mathrm{c}}$, Walter Wittich ${ }^{\mathrm{d}, \mathrm{e}, \mathrm{f}, *}$, Kate Dupuis ${ }^{\mathrm{g}}$, Marilyn Reed ${ }^{\mathrm{h}}$, Shirley Dumassais ${ }^{\mathrm{d}, \mathrm{e}}$, Paul Mick ${ }^{\mathrm{i}}$ and M. Kathleen Pichora-Fuller ${ }^{\mathrm{j}}$

${ }^{a}$ KITE - Toronto Rehabilitation Institute, University Health Network, Toronto, ON, Canada

${ }^{\mathrm{b}}$ Rehabilitation Sciences Institute, Temerty Faculty of Medicine, University of Toronto, Toronto, ON, Canada

${ }^{\mathrm{c}}$ Lawrence S. Bloomberg Faculty of Nursing, University of Toronto, Toronto, ON, Canada

dÉcole d'optométrie, Université de Montréal, Montréal, QC, Canada

${ }^{\mathrm{e}}$ Institut Nazareth et Louis-Braille du CISSS de la Montérégie-Centre, Longueuil, QC, Canada

${ }^{\mathrm{f}}$ Centre de réadaptation Lethbridge-Layton-Mackay du CIUSSS du Centre-Ouest-de-l'Île-de-Montréal,

Montréal, QC, Canada

${ }^{\mathrm{g}}$ Sheridan Centre for Elder Research, Sheridan College, Oakville, ON, Canada

${ }^{\mathrm{h}}$ Audiology, Baycrest Health Sciences, Toronto, ON, Canada

i Department of Surgery, Faculty of Medicine, University of Saskatchewan, Saskatoon, SK, Canada

${ }^{\mathrm{j}}$ Department of Psychology, University of Toronto, Toronto, ON, Canada

Accepted 7 September 2021

Pre-press 4 October 2021

\begin{abstract}
.
Background: Hearing loss is highly prevalent in older adults, particularly among those living with dementia and residing in long-term care homes (LTCHs). Sensory declines can have deleterious effects on functioning and contribute to frailty, but the hearing needs of residents are often unrecognized or unaddressed.

Objective: To identify valid and reliable screening measures that are effective for the identification of hearing loss and are suitable for use by nursing staff providing care to residents with dementia in LTCHs.

Methods: Electronic databases (Embase, Medline, PsycINFO, CENTRAL, and CINAHL) were searched using comprehensive search strategies, and a stepwise approach based on Arksey \& O'Malley's scoping review and appraisal process was followed.

Results: There were 193 scientific papers included in the review. Pure-tone audiometry was the most frequently reported measure to test hearing in older adults living with dementia. However, measures including self- or other-reports and questionnaires, review of medical records, otoscopy, and the whisper test were found to be most suitable for use by nurses working with older adults living with dementia in LTCHs.

Conclusion: Although frequently used, the suitability of pure-tone audiometry for use by nursing staff in LTCHs is limited, as standardized audiometry presents challenges for many residents, and specific training is needed to successfully adapt test administration procedures and interpret results. The whisper test was considered to be more suitable for use by staff in LTCH; however, it yields a limited characterization of hearing loss. There remains an urgent need to develop new approaches to screen hearing in LTCHs.
\end{abstract}

Keywords: Aging, cognitive impairment, dementia, hard-of-hearing, hearing impairment, hearing screening, long-term care home, nursing, scoping review

\footnotetext{
*Correspondence to: Walter Wittich, School of Optometry, 3744, rue Jean-Brillant, Bureau 260-7, Montréal, Québec H3T
}

1P1,Canada. Tel.: +1 5143437962 ; E-mail:walter.wittich@umon treal.ca. 


\section{INTRODUCTION}

\section{Hearing impairment, cognitive decline, and multi-morbidity}

Hearing impairment is one of the most prevalent chronic conditions affecting older adults [1-4], and is a leading contributor to disability globally [5]. The prevalence of hearing impairment increases markedly with age. Using criteria based on pure-tone audiometric detection thresholds, approximately half of older adults have clinically significant hearing loss by 75 years of age, with more than $80 \%$ affected by 80 years of age [6-8]. Age-related changes in audiometric thresholds can result from damage to the sensory cells and/or from metabolic changes in the inner ear [9]. Neural changes can also occur throughout the auditory system, from synaptopathy in the inner ear [10] to reduced brain volumes at higher cortical levels [11].

Significant associations between age-related declines in hearing and cognition have been found across several cognitive domains [12, 13]. For those with typical age-related declines in auditory and cognitive processing, listening may be relatively easy in favorable communication situations, such as when attention is focused on conversation with a familiar person in a quiet place with no distractions. However, it is often difficult to understand speech in less favorable everyday communication situations, when background noise, group interaction, and multi-tasking demands often co-occur (for a review, see Pichora-Fuller et al. [14]). Amplifying sounds can help, but this does not fully overcome the difficulties that older adults experience in complex listening situations. Notably, even when words have been correctly heard, they may not be remembered as well when listening occurs in noisy compared to quiet conditions, due to increased cognitive demands during listening [15].

The connections between auditory and cognitive functioning are disrupted further as hearing thresholds worsen. The severity of hearing loss has been directly associated with cognitive decline in older adults [16]; this association can begin even when audiometric thresholds are still be within the clinically normal range [17]. The risk of dementia increases as the degree of threshold hearing loss worsens [18]. Furthermore, the long-term effects of auditory decline are implicated in changes at a neural level [19], with evidence suggesting that central auditory dysfunction, as measured on dichotic speech tests [20, 21], may be a prodromal symptom of Alzheimer's disease [22]. Indeed, at the population level, the estimated risk for dementia is reportedly greater for hearing loss than for all other potentially modifiable risk factors at mid-life [23].

With population aging and life expectancy increasing, the prevalence of hearing loss, dementia, and many other chronic health conditions is rising. Multimorbidity, defined as two or more chronic conditions in one individual $[24,25]$, affects the majority of adults aged 65 and older [24, 26], with its prevalence predicted to double over the next 20 years [27]. Hearing loss has the potential to contribute to and interact with the multiple comorbidities that increase the risk of dementia [16] and can curtail healthy life expectancy when combined with neurological disorders [28]. Importantly, factors that contribute to frailty, including dementia [29], falls [30], and poor psychosocial health [31], as well as poor physical health and impaired activities of daily living [32], have all been associated with hearing loss. These factors are further compounded when declines in hearing, especially in combination with cognitive decline, make communication and social interaction challenging, which can lead to isolation and depression in older adults [33-35]. Individuals living with multi-morbidity are at greater risk of becoming care dependent, and adults with dementia are among those at highest risk of long-term care dependency $[26,36]$.

Crucially, managing hearing loss could be a valuable part of care for older adults, especially those living with dementia, multi-morbidities, or frailty [37]. The 2019 World Health Organization guidelines for Integrated Care of Older People (ICOPE) [38] has identified hearing as one of the key capacity domains for functioning. In particular, sensory and cognitive impairments are very common, and managing hearing loss could be beneficial for those living with dementia, including residents of long-term care homes (LTCHs).

LTCHs, also referred to as nursing homes, provide a combination of housing, medical, and personal care services for people who need ongoing daily assistance over extended periods of time. Research conducted across five LTCH settings in the United States found that over $80 \%$ of residents aged 60 years and older had at least mild hearing loss, with approximately $50 \%$ having moderate-to-severe hearing impairment that would render speech largely inaudible [39, 40]. Across studies conducted in Australia and Canada, more than half of LTCH residents have been found to be living with dementia, with 
behavioral symptoms of dementia found in more than $70 \%$ of residents [41-43]). Not surprisingly, with the average age of LTCH residents in Ontario, Canada, found to be 87 years, some degree of cognitive impairment has been identified in $94 \%$ of residents, with almost one third living with both cognitive impairment and dual sensory (hearing and vision) impairments that have compounding functional consequences [42]. Still, very low rates $(<10 \%)$ of hearing aid use have been reported [42]. Moreover, LTCH environments are often challenging for residents experiencing cognitive and sensory loss, even more so during the recent COVID-19 pandemic, due to mandated measures for infection prevention and control, such as distancing, mask wearing, and reliance on technology over in-person social and communicative interactions.

\section{Hearing screening}

Hearing screening, to identify the presence of hearing loss or monitor for changes in hearing, is a necessary step in managing hearing problems so that functioning in everyday life can be optimized. The World Report on Hearing proposes universal hearing screening for older adults [44]. In some countries, existing practice standards advise that adults be screened for hearing loss as needed or requested, and with increasing frequency after the age of 50 years, particularly in those who are vulnerable to risk factors associated with hearing loss [45]. In addition, hearing screening has been recommended for those who are being assessed for dementia [46]. Depending on the results of hearing screening, various recommendations can be made to improve communication functioning, with identification of a previously undiagnosed hearing loss or changes in hearing typically triggering referral for a full audiologic assessment and rehabilitation [45].

The methods used to test hearing will depend on the specific purpose of testing, the setting, and the qualifications of the tester. Assessing the degree and type of hearing loss, and planning rehabilitation, may involve otoscopy to inspect the ear canal and ear drum for problems such as impacted cerumen (wax) or infection, physiological tests to examine different levels of the auditory system from the ear drum to the cortex, behavioral tests to evaluate different auditory abilities, and questionnaires to measure self-reported or other-reported communication functioning and socio-emotional experiences of and reactions to hearing problems. The most common behavioral test is pure-tone audiometry, which is used clinically to measure hearing thresholds (an individual's ability to detect simple pure tones). It is also common to use behavioral tests to measure supra-threshold auditory abilities such as an individual's ability to understand words presented in quiet or in noise, using either one ear at a time (monaural tests), or using both ears, with either the same (diotic tests) or different (dichotic tests) information presented to the ears. As healthcare professionals qualified to measure hearing using a wide range of basic and specialized tests, audiologists have the training and expertise to modify the administration of tests if adaptations are needed for individuals who are unable to complete standard testing procedures. Given their advanced training and specialized clinical settings, audiologists can usually obtain reliable test-retest hearing assessment results for those living with mild levels of dementia [47].

People living with dementia are among those for whom non-standard testing methods may be needed [48-50]. Although audiometry can be successfully administered in audiology clinics to test hearing in people living with dementia, its suitability for use by non-audiologists to screen people living with dementia is limited by the need for specialized expertise to adapt test procedures for many of these individuals. Even though evidence-based practice guidelines devised for front-line nursing staff in care facilities recommend the use of otoscopy and pure-tone audiometry [51, 52], it is important to complement these with staff- and self-reporting tools to evaluate a resident's level of activity and participation in the LTCH [39]. Yet, the shortage of regulated nurses in most LTCHs and a lack of training in the use of these tools likely precludes the implementation of these recommendations [53], while referral for ear and hearing care following screening may not be prioritized or regularly implemented.

In light of mounting evidence implicating hearing loss in neurocognitive decline, there is an imperative to develop and evaluate approaches to screen hearing that are suitable for administration by nonaudiologists working with older adults who are living with dementia [54, 55]. Simple, low-tech measures, such as the whisper [56] and finger rub tests [57], are commonly used by primary care physicians and neurologists who recognize the need to screen for hearing impairment in older adults who are at risk [58-61]. Although the complexity and progressive nature of dementia-related symptoms necessitates the involvement and collaboration of many health professionals $[62,63]$, audiologists are seldom included as 
members of inter-professional teams and the presence or severity of hearing loss is an aspect of the individual's impairment profile that is often under-estimated by the other health specialists within the circle of care $[50,64,65]$.

In addition to the consequences of hearing loss for everyday functioning, hearing loss is also important to consider because it can affect other assessments of individuals who may have comorbid conditions. Importantly, hearing loss can negatively affect performance on the most frequently used screening tests for cognition, such that tests administered verbally can result in an over-estimation of the presence or level of cognitive impairment when sensory impairments are not considered $[66,67]$. The presence and severity of hearing impairment has not only been found to be under-estimated by the specialists tasked with the assessment and diagnosis of cognitive disorders [64, 65], but also by the health professionals responsible for the care of older adults living with dementia, many of whom may have multiple comorbidities [50].

It has been recommended that hearing be assessed when residents are first admitted to an institutional residence, as well as on an ongoing basis to monitor for change [48]. In institutional care settings around the world, the standardized Resident Assessment Instrument (RAI) Minimum Data Set (MDS) is the most commonly used assessment tool (http://www. interrai.org). The RAI-MDS is designed to collect data across many domains regarding residents' strengths, needs, and potential risks for the purposes of guiding care planning and monitoring [68]. According to the RAI-MDS protocol, a resident should be assessed upon admission and re-evaluated on a quarterly and at least annual basis, as well as upon detection of a significant change in a resident's health or functional status [69]. The information gathered for the assessment may be based on records of audiologic assessments or hearing aid use noted during chart review, observation of the resident's communication abilities, or ratings of hearing abilities by the resident or key informants such as family members or care providers. RAI-MDS ratings of hearing ability correlate significantly with the results of pure-tone audiometry [70], and other common screening measures, such as the Hearing Handicap Inventory for the Elderly (HHIE-S) [71]. Still, hearing impairment in residents is often not identified using the MDS [70, 72].

In general, estimates of the prevalence of hearing loss in older adults are higher when behavioral tests are used compared to when self-report measures are used to identify hearing loss [73-75]. When records of audiologic assessments are not available during chart review, the MDS relies heavily on self-report or other-report of a resident's hearing loss and hearing aid use, with under-reporting of hearing problems leading to lack of referral of residents with hearing loss for audiologic assessment and rehabilitation [76]. Consequently, there are reductions in the quality of life and provision of care for those whose hearing loss has not been addressed [77-80].

The assessment and management of hearing needs in persons living with moderate to severe dementia can add even more challenges. Health professionals working in LTCHs may observe the communication difficulties or withdrawal of a resident, but attribute the source of these difficulties to cognitive impairment without recognizing the contribution of hearing impairment $[41,72]$. Nursing and other care professionals have reported challenges in distinguishing between the symptoms of dementia and hearing impairment insofar as both affect communication [41, 81], and they have expressed interest in accessing further education, as well as learning better ways to screen hearing and how to use the results to better tailor the provision of care [81].

Compared to residents with cognitive impairment alone, those who have combined cognitive and hearing impairments are more likely to have communication problems, as well as reduced social interactions and participation (e.g., in group activities). These problems are even greater in residents who have impairments in hearing, vision, and cognition [42]. Increased awareness of sensory problems, their co-occurrence with cognitive decline and increased functional burden, and how these can be alleviated, could provide key information to the planning and provision of care and accommodations within LTCH environments. More effective hearing screening could also result in more effective management of hearing problems of residents living in LTCHs, to improve communication functioning, social interaction, and overall well-being.

\section{The present study}

The purpose of the present study was to conduct a scoping review of the literature to determine which hearing screening methods have been used to assess people who are living with dementia. A second step was to then identify which of these screening methods are reliable and valid tests that would be suitable for use by nurses working in LTCHs. As part of 
a larger mixed-methods investigation [82], our aim was to find suitable methods for screening hearing to identify residents in need of referral to a hearing health care professional. Screening and referral were assumed to be prerequisites for an evidence-informed approach to care for residents in LTCHs that would result in appropriate interventions for hearing loss and improved quality of nursing care, which would facilitate more effective communicative interactions, improved functioning, and greater engagement in daily activities for residents. Better management of hearing problems could also potentially help mitigate declines.

\section{MATERIALS AND METHODS}

Following a study protocol and scoping review methodology previously described [82, 83], a stepwise approach based on Arksey \& O'Malley's scoping review process was undertaken [84]. A scoping review methodology was used to allow for an extensive investigation of the existing literature to identify the range and degree of research activity that could answer a broad research question, while also identifying any gaps in the current evidence base [84]. An assessment of the methodological rigor and quality of the included studies, formally associated with a systematic review, was not conducted; however, the literature search and reporting of results was systematically carried out [85].

\section{Identifying the research question}

The question that the research sought to answer was which hearing screening measures and approaches have been used effectively to identify hearing loss in older adults with dementia living in LTCHs [82]. We aimed to provide an overview of the measures used to screen the hearing of persons living with dementia as reported in the literature, and to summarize the reported reliability, validity, and sensitivity of these measures. Screening measures for hearing loss were defined as tools, tests, or instruments used in the preliminary evaluation of hearing ability, without necessarily measuring the degree of hearing loss or diagnosing the nature of the impairment.

Search terms were formulated, trialed, and revised by an Information Specialist at the Toronto Rehabilitation Institute-University Health Network, before then being incorporated into search strategies appropriate to each database (Supplementary Material). Keywords to search for the concepts of hearing screening, long-term care settings, and dementia in the literature included, but were not limited to: hearing, auditory, audiologic or dual sensory testing, screening, assessment, or evaluation; persons with hearing disorders/impairment, or deaf-blind disorders; long-term care, nursing home, or homes for the aged; dementia, Alzheimer's/neurodegenerative disease, or cognitive disorders; aged, elderly, geriatric, older, or senescent.

\section{Identifying relevant studies}

Four databases (Embase, Medline, PsycINFO, CINAHL) and the Cochrane Central Register of Controlled Trials (CENTRAL) were searched using formulated strategies (Supplementary Material), with searches limited to research published between January 1995 and January 2020; further updates were not undertaken after the onset of the COVID-19 pandemic. No limitations were placed on the type of research or the language in which it was reported, so that peer reviewed as well as non-peer reviewed publications were captured, including conference proceedings and academic dissertations. Research reported in a language other than English was interpreted by multi-lingual members of the study team or by use of translation software (Google Translate). Specifically, six reports in French, German, and Spanish were reviewed by members of the team with proficiency in these languages; whereas reports in Dutch, Portuguese, Italian, Mandarin, or other were translated by use of online tools with only the relevant study information judged for eligibility, and then extracted in five that were included.

\section{Study selection}

Reference management software (EndNote, Clarivate Analytics) was used to collate the resulting citations and remove duplicate results. Citations were exported into a spreadsheet format. The title and abstract of each paper were screened by two independent reviewers, who coded citations for inclusion or exclusion in accordance with agreed criteria (Table 1). Any discrepancies were discussed between the reviewers, and if consensus could not be reached on the study's inclusion or exclusion, disagreements were arbitrated by a third reviewer. Studies reporting on the screening for hearing loss in participants or clinical groups aged 65 years or older with a diagnosis of dementia or cognitive impairment were included in the review. 
Table 1

Procedure and exclusion codes for review: The raters were instructed to exclude a study using the first exclusion code that applied from the following criteria and to flag if they were uncertain about excluding a study. All studies not excluded were included

\begin{tabular}{|c|c|c|}
\hline Code & Criteria & Rationale \\
\hline \multirow[t]{2}{*}{1.} & Participants & Not neurodegenerative/dementia, or not human (e.g., mice, primates) \\
\hline & & Note: Patients with Parkinson's disease were included unless specified as non-demented \\
\hline \multirow{2}{*}{2.} & Not Hearing & Does not use hearing assessment tools/instruments \\
\hline & & Note: exclude verbal learning test of memory \\
\hline 3. & Age & Only participants $<65$ years \\
\hline 4. & Report Type & Editorial, review, expert opinion, book \\
\hline 5. & No Abstract & Cannot be judged due to missing abstract \\
\hline 6. & Duplication & More than one citation of same article \\
\hline 7. & Publication year & $<1995$ \\
\hline \multirow[t]{2}{*}{8.} & Error & Database error (e.g., scrambled citation) \\
\hline & Include & Hearing assessment in neurodegenerative participants $\geq 65$ years \\
\hline
\end{tabular}

\section{Charting the data}

After a full review of articles, data from the final set of accepted studies were extracted by two reviewers to populate a formulated spreadsheet, including the following: author(s), year of publication, country, type of testing environment (e.g., clinic, research laboratory, LTC facility, or other), study design, sampling method, participant demographics (age, gender, dementia type, and disease severity), name of hearing measure, auditory ability assessed, reported psychometric properties (validity, reliability, sensitivity, and specificity), as well as any details pertaining to the sensibility of tests. Sensibility was specified as the feasibility and acceptability by users and administrators of the test in the environmental and patient context of test administration [86, 87]. Details relevant to the measure's sensibility included any adaptations to test administration for the clinical population, the number of participants who could not complete the test, and any specific training or qualifications required for test implementation or interpretation [82].

\section{Summarizing and reporting the results}

Incorporating an optional component of Arksey and O'Malley's scoping review methodology, accredited practitioners with expertise in hearing and dementia care were also consulted during the review process [84]. As part of this second step of appraisal, two audiologists, an otologist, and a neuropsychologist, who all had expertise in hearing functioning in older adults experiencing cognitive impairments, reviewed and rated the suitability of the extracted tests for their use by nurses in LTCHs to screen hearing in residents with dementia. Two experts reviewed the selected studies to identify the hearing tests that were used and to categorize them in accordance with the domain of ear and hearing status evaluated. Finally, all four experts appraised the tests for their potential suitability. In judging suitability, the reviewers considered pre-determined factors that included the availability and cost of required test equipment, the level of specialized training needed for test administration and interpretation, whether the test procedures fell within the scope of practice of nurses, and the test's suitability for testing residents in LTCH settings. Any discrepancies in the judgements of suitability were explored through face-to-face discussion and then reconciled among the four experts.

\section{RESULTS}

\section{Data extraction}

Five databases were searched on the 13 January 2020 , yielding 2,333 identified publications. After duplicates were removed, 301 papers selected for full-text review were assessed for eligibility in the final scoping report. A further 108 studies were excluded, resulting in 193 papers describing research in older adults with dementia and/or cognitive impairment, which contained tests that potentially could be used by nurses to screen hearing in this population (see PRISMA flow chart in Fig. 1).

\section{Cognitive status of participants}

A mixture of dementia types, unspecified dementia or cognitive impairment indicative of dementia was most frequently reported, across almost half the reviewed studies $(n=86)$, but the most common diagnosis among participant groups was dementia of the Alzheimer's type $(n=59)$. In cases where disease severity was reported, studies mainly included par- 
Identification of studies via databases and registers

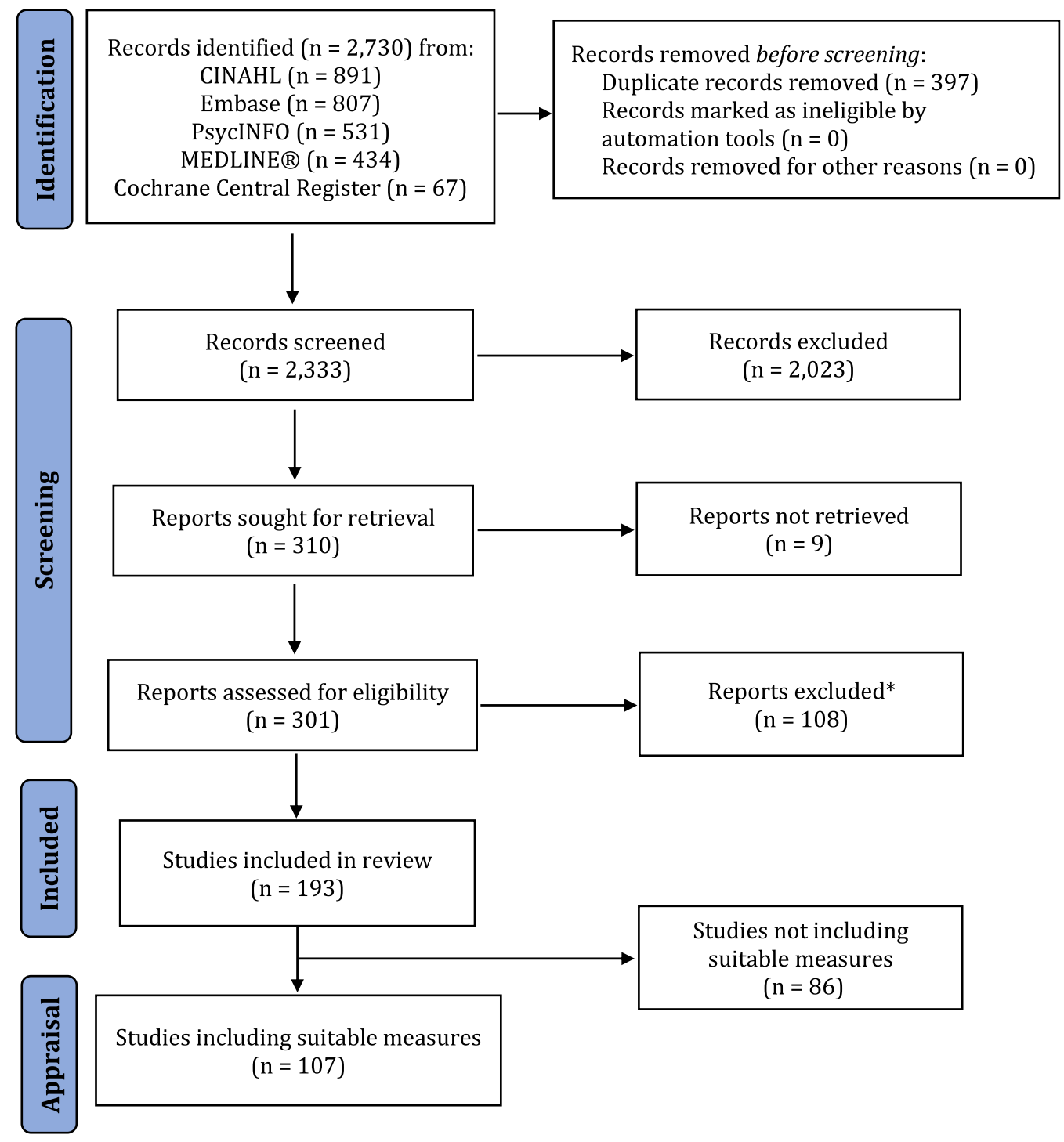

* Final exclusion by consensus between raters, without consensus on reasons for exclusion.

Fig. 1. PRISMA 2020 Flow Diagram [291].

ticipant groups with between mild to severe $(n=51)$ or mild to moderate cognitive impairment $(n=41)$. Approximately $10 \%$ of the studies reported testing the hearing of individuals with mild dementia alone $(n=20)$, and fewer reported on the testing of only participants who were moderately $(n=4)$ or severely cognitively impaired participants $(n=2)$; whereas most research reports did not describe the severity of dementia of their participants $(n=71)$.

\section{Study test environments}

Of those studies reporting on the testing environment, a clinical setting was the most frequently reported (71 studies). For 42 studies, hearing was evaluated within the LTCH setting, and an additional 15 studies were conducted across two or three settings, which included LTCHs, private residences, and community centers. A further 15 studies involved measures administered in participants' private res- 
idences alone, while 18 studies were conducted exclusively in a research environment, and 30 studies did not specify the environment in which assessment data was collected.

\section{Data analysis}

The tests extracted from the review were categorized by the expert reviewers to indicate which aspect of ear and hearing status was being tested (e.g., puretone audiometry versus speech understanding), as well as differences among measurement approaches (e.g., self-report, or behavioral or physiological test), or whether the measures involved the examination of anatomical structures (e.g., presence of cerumen) or functional aspects of hearing (e.g., other-report measure). Although the majority of studies $(n=121)$ reported relying on only one method of screening, more than a third of the studies $(n=72)$ described the use of more than one method to evaluate the hearing of participants. Overall, 87 different screening measures were identified and grouped by category, while two further measurement approaches were not described sufficiently for categorization.

\section{Expert appraisal}

More than one third $(n=33)$ of the identified tests or measurement approaches were judged to be suitable for use by nurses to screen for hearing loss in older adults living with dementia (see Table 2). Of the 56 tests deemed not to be suitable, many were tests that are commonly part of a clinical hearing assessment battery, but these tests were deemed unsuitable for use by nurses to screen residents with dementia in LTCH, most often due to the requirements of specialized or costly equipment and/or training. Excluded for these reasons were specialized behavioral tests of higher-level auditory processing $(n=20)$, physiological tests such as auditory evoked potentials $(n=5)$, middle ear testing $(n=4)$, and otoacoustic emissions $(n=2)$. Notably, although they are common audiologic measures, pure-tone audiometry $(n=3)$ and speech testing $(n=14)$ were deemed unsuitable for use by nurses in LTCHs due to the need for specialized equipment and training for their administration and interpretation. Assessment by use of a tuning fork $(n=1)$, and questionnaires focused solely on hearing aid use or without the inclusion of questions relevant to hearing ability $(n=5)$ were also deemed unsuitable for determining if a person had a hearing loss. Two more measurement approaches lacked sufficient detail for evaluation. The identified measures were deemed to be unsuitable for the aforementioned reasons, but none were eliminated because they were beyond the scope of practice of nurses.

From the total of 193 studies in the review, 107 studies used at least one test considered to be suitable [42, 70, 72, 77, 88-190], whereas 86 research articles did not describe implementing any of the measures deemed suitable [8,21, 191-274]. All suitable tests conducted in studies in which their testing environment was described ( $n=71$ studies) are shown in Table 2; an additional seven studies cited the use of suitable tests but without specification of the testing environment [89, 90, 186-190].

Of all tests identified, whether they were deemed to be suitable or unsuitable for use by nurses in LTCH to test residents living with dementia, the frequency with which specific psychometric properties were described across all included studies were: reliability ( $n=23$ studies), validity $(n=10)$, and sensitivity and/or specificity $(n=9)$, with multiple test properties reported for some tests. The investigation of the psychometrics properties of tests were most often reported for pure-tone audiometry $(n=11)$, speech testing $(n=4)$, auditory attention tests $(n=4)$, self-report measures $(n=2)$, or otherreport measures $(n=2)$. Test-retest reliability was the most often reported test property. However, studies also reported on the unreliability of testing, including that of pure-tone audiometry and self-report measures [123]. Some studies also reported that where reliable results were obtained, repeated instructions were required to overcome challenges in communication in order to obtain valid responses [274]. Across studies, sometimes one study reported on the validity of a measure, such as the RAI MDS questionnaire [171], but findings were not always consistent with those of other studies [72].

Notably, the administration of hearing measures described in the papers also included considerations for the sensibility of the testing approach. Across all studies, there were 161 reports of the test administration requiring either adaptations to standard administration procedures, exclusion of participants with moderate or severe dementia due to inability to complete the test reliably, or requirements for specific training of the test administrator. Again, the reported sensibility of test administration most frequently involved pure-tone audiometry (35 studies), self-report or other-report measures $(n=41)$, auditory evoked potentials $(n=9)$, speech testing $(n=8)$, central auditory processing $(n=8)$, middle ear test- 
Table 2

Hearing tests deemed suitable for screening older adults living with dementia in LTCH, with citations listed in columns corresponding to the reported setting of test administration. Citations are highlighted with an asterisk if instances of sensibility were reported (i.e., cases in which test administrated was amended, participants excluded, or training for test administrators referenced)

\begin{tabular}{cccc}
\hline Category of Test & Name of Test or Procedure & $\begin{array}{c}\text { Long-term Care and } \\
\text { Residential Settings } \\
\text { (inc. private homes) }\end{array}$ & $\begin{array}{c}\text { Clinical Settings } \\
\text { (inc. hospitals) }\end{array}$ \\
\hline
\end{tabular}

(inc, private homes)

$[138]^{*}$

Outer Ear Care Questionnaire - assessing participants' frequency of ear

[120]

cleaning, cerumen type, and incidence of itching within the

ear canal

Otoscopy ${ }^{\mathbf{R}}$ with cerumen (wax) removal

$$
\begin{array}{cc}
{[70]^{\mathbf{R} *[72]^{*}[88][174]^{*}}} & {[105]^{*}[123]^{\mathbf{R} *[131]^{\mathbf{R}}}} \\
{[181][188]^{\mathbf{R} *[182]}} & {[133][140][141]^{*}[144]} \\
& {[148]^{*}[149]^{*}[151][152]}
\end{array}
$$

Chart Review Review of medical records - documentation of hearing impairment, audiometry, and ear cleaning

Other Report Observation as measure of severity of hearing loss - showing

clear hearing difficulties during the interview with the examiner

Nursing Home Hearing Handicap Index for carer (NHHHIC)

Hearing Handicap Inventory for the Elderly (HHIE)

[137] [147] [136] [135]

[106 $]^{*}$

[72]* [77] [166] [176] [192]*

$[134]^{*}$

$[190]^{*}[193]^{*}[184]^{*}$

$[166]^{*}$

[88] [119] [133]

carer-assessment

$[126]^{*}$

$[126]^{*}$

Hyperacusis questionnaire (modified version)

Combined Serious Sensory Impairment interview screen

$[148]^{*}[149]^{*}$

Multidimensional Dementia Assessment Scale (MDDAS)

Minimum Data Set (MDS 2.0 or 3.0) Communication/Hearing

Patterns Section and Functional Hearing Impairment

questions

interRAI Long-Term Care Facilities Assessment (interRAI

LTCF

interResident Assessment Instrument-Acute Care

(InterRAI-AC)

Resident Assessment Instrument for Home Care (RAI-HC)

Medical and Psychiatric Diagnosis Form (MPDF)

$[72]^{*}[77][175]^{*}[177]^{*}$

[180] [185] [186]* [187]*

[194]

$[168]^{*}[170]^{*}[169]^{*}[171]^{*}$

$[172]^{*}[173]^{*}$

$[148]^{*}[149]^{*}$

$[161]^{*}[162]^{*}$

[192]*

[42] 
Table 2

(Continued)

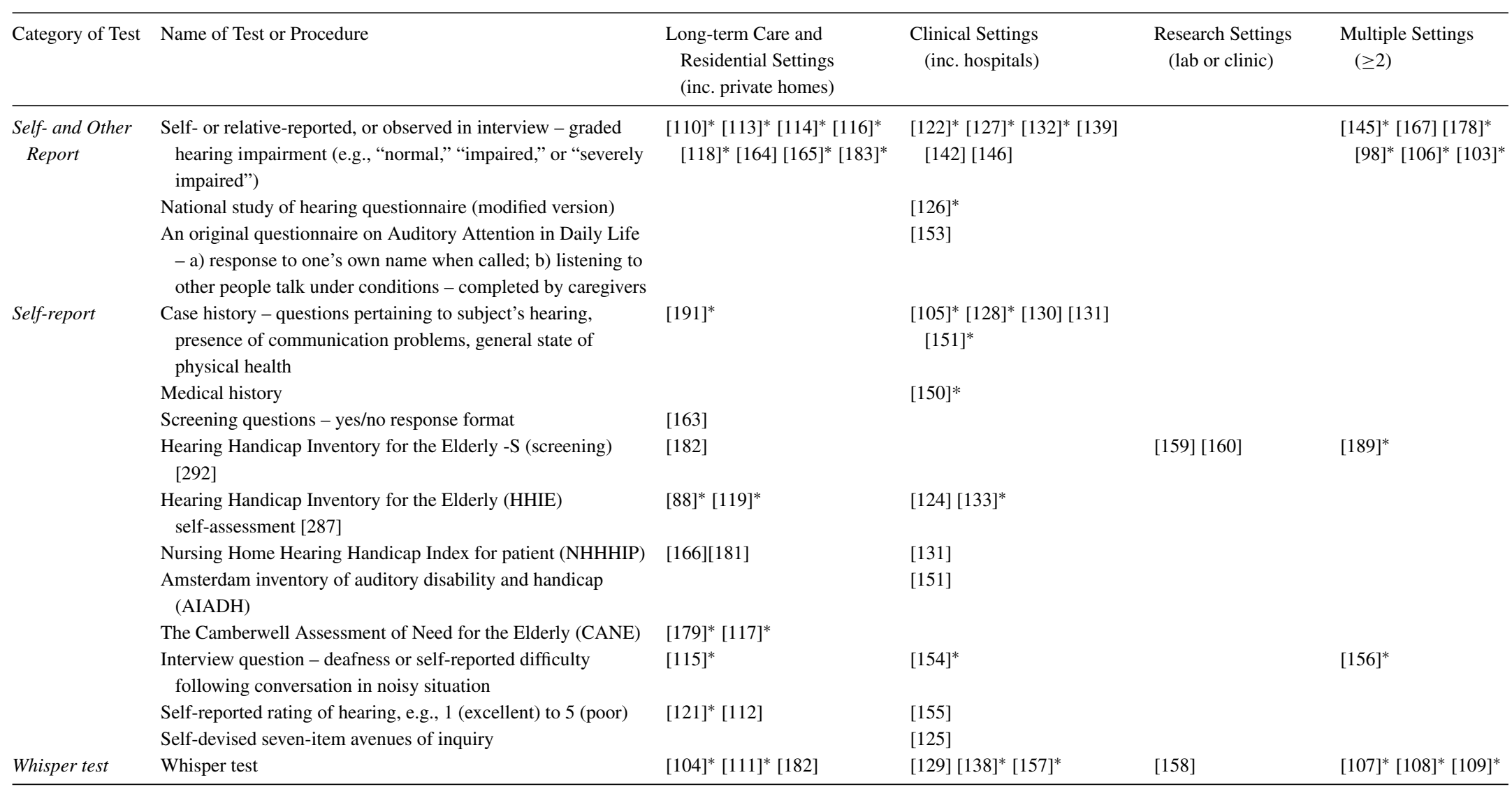


ing $(n=7)$, as well as the whisper test $(n=7)$. In the case of the whisper test, sensibility was considered most often in terms of the test administrator's qualifications, whereby it was noted that the test was conducted by nursing or geriatric medical professionals. Based on the criteria for suitability, the screening tests shown in Table 2 were suggested as a starting point for staff working in nursing homes.

Measures that were judged to be suitable for use by nurses with older adults living with dementia were mostly cited in studies conducted in LTCH, nursing home, private residential or clinical care settings, and were also described as allowing for some adaptation when used with participants living with dementia (studies highlighted with an asterisk in Table 2). For suitable measures of self- and other-reports, as well as evaluation of a person's ear health and audiologic history, the adaptability of these measures and the inclusion of family and carer information may be seen as critical factors for their successful administration. Not all questionnaires or report measures addressed the respondent's hearing alone, but they included questions that would be suitable to screen for hearing loss in older adults living with dementia; for example, the American Speech-Language-Hearing Association Functional Assessment of Communication Skills for Adults (ASHA FACS) [190], Camberwell Assessment of Need for the Elderly (CANE) [275], Multi-Dimensional Dementia Assessment Scale (MDDAS) [276], and the Resident Assessment Instruments [277]. The screening approaches judged to be unsuitable for use by nurses with older adults living with dementia were more likely to be have been implemented in clinical or research environments, with adaptations for use more often requiring the expertise of specialist clinicians and researchers.

\section{DISCUSSION}

This scoping review sought to answer the question of which hearing screening measures and approaches have been effectively used to identify hearing loss in older adults living with dementia, with a view to finding reliable and valid tests that would be suitable for use by nurses working in LTCHs. The identification of residents who have hearing problems is critical for determining the need for referral to a specialist or for accommodating accessibility needs (e.g., use of assistive technology or communication strategies), and for informing person-centered care. The identification of residents who have hearing loss is necessary so that appropriate accommodations are implemented to better support successful communication, meaningful engagement in everyday activities, quality of care, and to thereby delay or reduce the risks of further cognitive decline, such as social isolation in LTCHs. As there is a heightened need for suitable and validated screening measures for the identification of hearing loss in persons living with dementia that can be used across LTCH settings by nursing professionals, the focus of this discussion will center on the tools which could be suitable for use in this setting by these staff.

\section{Suitable measures for the screening of hearing in adults living with dementia}

The review found that a wide range of measurement approaches have been used to measure aspects of hearing and auditory functioning in individuals living with dementia, including subjective measures (based on self- or other-reports), behavioral measures (requiring a patient response to tones or speech), and physiological measures (examining the ear canal for cerumen [wax], immittance to assess middle ear function, otoacoustic emissions to evaluate inner ear status, or evoked response potentials to examine auditory brain responses). Pure-tone audiometry was the most frequently reported hearing test.

The consulted team of accredited healthcare professionals with expertise in the assessment of older adults living with hearing loss and dementia identified a subset of the hearing screening measures extracted in this scoping review that were deemed to be suitable for nurses to use in order to screen the hearing of residents living with dementia in LTCHs. Suitable measures included measurement approaches involving otoscopy to determine the need for cerumen management, in addition to the use of interview questions, collecting relevant hearing and ear disease history from medical charts, and using questionnaires such as the Nursing Home Hearing Handicap Index for the patient and the carer [278], the Hearing Handicap Inventory for the Elderly [279], as well as questionnaires and inventories to screen for tinnitus and hyperacusis. The whisper test was found to be the most suitable behavioral measure. The suitability of these measures was based on procedures falling within the scope of practice of nurses with no prohibitive requirements for specialized or costly equipment or extensive training.

The review indicated that a noteworthy proportion of adults with cognitive impairment were unable to complete standard test protocols or required the tester 
to modify the procedures used to administer tests. Sensibility issues were noted for 54 tests. In many studies conducted across various settings, patients or residents living with severe or very severe dementia were excluded from the outset if measures involved verbal reporting or other behavioral responses [122, $140,197]$. In one study [246], despite audiometric testing being led by certified and experienced audiologists, the majority of 307 participating nursing home residents were unable to perform standardized pure-tone or speech audiometry, with over half (54\%) not completing reliable audiologic assessments due to dementia or "dementia-characterized behaviors". Among participants whose hearing was successfully screened using pure-tone audiometry, the majority were found to have hearing problems, but those identified as having problems were older and performed more poorly on cognitive measures compared to those without hearing problems [140]. Overall, a large proportion of studies relied on the expertise of audiologists or geriatricians to implement hearing assessments with appropriate adaptations to test procedures for individuals experiencing more severe cognitive impairment. These findings bring to light the importance of the testing environment (i.e., a quiet location), as well as the training required to successfully administer screening tests with knowledge of how to adapt standard procedures to the cognitive capacities and abilities of the individuals being screened. Thus, almost two-thirds of hearing tests identified in the present review were not found to be suitable for nurses to administer in LTCHs.

\section{Suitable measures for the screening of residents in LTCH settings}

The testing environments reported in the studies included various clinical settings (memory clinics, primary care centers, and geriatric departments of hospitals), as well as research laboratories and clinics, and private residences. However, less than a quarter of the studies included in the review focused on testing residents in LTCH settings. We were most interested in the studies involving testing by nursing professionals in LTCHs, as both hearing loss and cognitive impairments are highly prevalent in residents living in LTCHs, and because residents with complex multi-morbidities must first be identified as requiring an evaluation of their hearing before being referred to the relevant audiologic or medical specialist. Finding a suitable testing space that is quiet and without distractions in LTCHs can be a challenge.
The requisite identification and referral for clinical assessment outside of the LTCH, however, may be lacking and may not be practical. Meanwhile, combined hearing and cognitive impairments will significantly affect the communication functioning and social interactions of residents and their overall quality of care. In LTCHs, the most frequently cited hearing screening approaches used by nurses were those that relied on self- and/or other-report measures. These measures could be simple yes/no questions about hearing problems and hearing aid use, observations made during a clinical interview, or the use of standardized questionnaires, review of medical chart data, or nursing report forms. As part of a comprehensive assessment system used in LTCHs, the interRAI Long Term Care Facilities (interRAI LTCF) and RAI-MDS have been designed to gather relevant clinical information across many functional domains to guide the treatment and care planning of older adults who may experience complex and multiple chronic conditions [280]. The interRAI LTCF, along with the RAI-MDS 2.0 and 3.0 were cited in $36 \%$ of the studies conducted in this care setting. However, the use of the interRAI LTCF as a screening tool has also been found to have some limitations. A series of reports by the investigators of the Services and Health for Elderly in Long TERm Care (SHELTER) study investigated sensory impairments among residents of 59 nursing homes in eight European countries based on the interRAI LTCF. A striking finding of these reports was that residents with "extremely severe cognitive impairment" were excluded due to inaccuracies in their assessments. Their exclusion highlights that, despite the interRAI LTCF being the most widely used screening measure in LTCHs worldwide, and even though it could include information provided by other professionals or clinical records, older adults with more severe impairments are at increased risk of not being identified as having hearing loss or needing referral to the relevant healthcare specialist $[160,161]$.

Other approaches that were used by nurses in the LTCH setting were reviews of medical records and charts, nursing assessment forms and questionnaires (e.g., Nursing Home Hearing Handicap Index for Carer; [278]), self- or other-reports, and observation of hearing difficulties. The use of self-report measures is a concern insofar as such measures typically under-estimate the presence of hearing loss that would be detected using behavioral tests such as audiometry [173]. In order to address inaccuracies in documented hearing impairments or discrepancies 
between self- and other-reports, additional education on observable indicators of hearing loss, as well as reporting biases, is warranted for healthcare professionals working with this patient population.

Additional approaches to hearing screening included some physical measures that could be used by nurses, such as screening otoscopy (5 studies), and behavioral approaches such as the whisper test $(n=6)$. Studies reported on the use of a whisper test across clinical, residential, and LTCH settings, without requiring any adaptations of the test procedure itself [94, 96-98, 148]. By testing the participants' ability to hear the examiner's whispered voice from a distance of $60 \mathrm{~cm}$, and by dichotomizing results as the presence or absence of hearing difficulties, the researchers found that a third of older adults presented with uncorrected hearing impairment. Testing was often conducted by "geriatric-trained" investigators; however, in one study, research nurses were trained to achieve satisfactory accuracy and inter-rater reliability in recognizing hearing loss as observed in response to speech and whispered voice during an interview [175]. Along with otoscopic examination, which already falls within the scope of nursing practice (for those who have completed a certification course), the whisper test has potential utility for nurses, once additional training has been provided. Nonetheless, these screening procedures are limited insofar as they do not provide information about the degree of hearing loss and cannot be used to quantify the degree of change in an individual's hearing status.

Several of the studies highlighted the role that nurses could play in conducting otoscopic evaluation to determine if ear care for residents is needed to remove impacted cerumen from the ear. Importantly, removal of cerumen occluding the ear canal to restore sound transmission to the eardrum has many benefits; it can improve hearing in more than 10\% of cases [121], as well as increasing the accuracy of audiometric testing, and enabling devices such as hearing aids to perform properly. In one study, two thirds of LTCH residents assessed by otoscopy had impacted cerumen, but this condition would not have been discovered from responses to selfreport measures alone [173]. In a study in which 15 residents were assessed by an experienced audiologist and student audiologists, one third of residents presented with wax occlusion, with three of these five residents having bilateral occlusion [172]. In another study, $52 \%$ of participating residents required removal of cerumen before their hearing could be evaluated accurately and, when comparing the results of audiometric assessment by an experienced audiologist with staff ratings on the RAI-MDS, $44 \%$ of residents had unidentified or underestimated hearing loss [70]. These results spotlight the need to physically examine the ear canal for impacted cerumen as a precondition to further assessment, as well as the need for training of the responsible healthcare professionals to undertake cerumen management. While nurses were reported to conduct otoscopy, referral to a specialist was typically made for cerumen removal [113]; however, in many jurisdictions, cerumen management is within the scope of practice for nurses who have completed certified training [51].

The administration of test measures by nurses in the LTCHs was predominantly reported in studies that used interRAI LTCF and RAI-MDS to gather data on residents' hearing status, with the exception of a cross-sectional survey of English residential homes by Mann and colleagues [175]. Across 17 homes, research nurses assessed residents' hearing ability by observing responses to "speech and whisper", with $40 \%$ of residents, the majority of whom had dementia, presenting with hearing difficulties. It was also found that staff recognition, responsiveness and quality of care provided to residents with sensory impairments, such as the updating of care plans and provision of aids, influenced the residents' experience of depression, with appropriate interventions associated with lower levels of depression in these residents [175]. This study indicates that the informal assessment of hearing by use of whispered voice can be implemented by nurses to successfully identify residents with dementia who are experiencing hearing loss. It also supports the development of the nurse's role in resident assessment, so that suitable and adaptable approaches can be used to screen residents for hearing loss, with the consideration of the resident's individual needs and capabilities, at a time and place that will also reduce any additional burden and thereby maximize the reliability of results. These are key factors which nursing professionals are precisely qualified to determine.

\section{Identified limitations and priorities for future research}

The present review found that the studies conducted in LTCH settings most frequently used either self- or other-report measures, or a combination of these measures with otoscopy and behavioral mea- 
sures (e.g., the whisper test) to screen for hearing loss in residents living with dementia. There have been recent efforts to establish the reliability of the most common audiometric measures for use with adults living with dementia [47, 49]. Although these approaches may be successful for screening hearing in adults with mild or even moderate cognitive impairment, the most often reported concern for the sensibility of test administration was the severity of cognitive impairment in older adults with dementia. In particular, reliable and feasible methods to screen hearing in those with severe dementia are still needed for nurses to use in a less controlled and more ecological manner, as would be required in the LTCH setting. The review did reveal an evident need for increased involvement of healthcare professionals working in LTCHs to identify residents with dementia who could benefit from appropriate referral and rehabilitation for hearing loss.

There is growing consensus on the need to identify and appropriately address hearing loss in older adults [23, 44]. Calls have been made for increased cross-disciplinary education of health and social care professionals, along with evidence-informed policy improvements, to address the need for increased awareness of sensory problems and better collaboration among care providers to adequately support individuals living with combined sensory and cognitive impairments [281]. With advances in digital and remote technologies [44], previous methods that relied upon specialized and costly equipment and training may become more accessible, ecological, and adaptable to the LTCH environment.

There are limitations to the current study, principally, that the team of experts who appraised the suitability of hearing instruments for use by nurses did not include the expertise of nursing professionals. Following the endorsement of specialists in both sensory and cognitive aging [282], a consequent study was conducted using the screening approaches judged to be suitable for use by nurses to screen for hearing loss in residents with dementia in a LTCH setting in order to test their feasibility and reliability, and with the results forthcoming.

\section{CONCLUSION}

While many tools and strategies have been used to measure hearing in older adults with cognitive impairments, most studies have been conducted in clinics or laboratories rather than in LTCH settings. In addition, most studies of hearing screening that have taken place in LTCHs have been conducted by specialists with specific training, and the experience to make necessary adaptations to test administration, not all of which is easily transferable to nursing staff. Identifying reliable, valid, and feasible hearing screening tools for nurses is a necessary step in this quest to develop new approaches and implement informed policies to identify hearing loss in residents living with dementia in LTCHs by the most appropriate, responsive, and practicable means, so that the sensory and communicative needs of affected residents can also be addressed.

\section{ACKNOWLEDGMENTS}

The database search was conducted by Jessica Babineau, an Information Specialist at the Toronto Rehabilitation Institute-University Health Network. We thank Dawn Guthrie, Jonathan Jarry, Xochil Argueta-Warden, Maxime Grossi, Morgan Hempinstall, Karine Elalouf, Huiwen Goy, and Swaathi Balaji for their contributions to this research. This work was financially supported by the Alzheimer Society Research Programme (ASRP), Alzheimer Society of Canada; grant number RG 16-08. Dr. McGilton is supported by the Walter and Maria Schroeder Institute for Brain Innovation \& Recovery. The sponsor had no role in conducting the study or preparing this manuscript. Dr. Wittich is supported by an FQRS Junior 2 chercheur boursier career award (\# 281454).

Authors' disclosures available online (https:// www.j-alz.com/manuscript-disclosures/21-5087r1).

\section{SUPPLEMENTARY MATERIAL}

The supplementary material is available in the electronic version of this article: https://dx.doi.org/ 10.3233/JAD-215087.

\section{REFERENCES}

[1] Pleis JR, Ward BW, Lucas JW (2010) Summary health statistics for U.S. adults: National Health Interview Survey, 2009. Vital Health Stat 10, pp. 1-207.

[2] Griffith LE, Raina P, Levasseur M, Sohel N, Payette H, Tuokko H, van den Heuvel E, Wister A, Gilsing A, Patterson C (2017) Functional disability and social participation restriction associated with chronic conditions in middle- 
aged and older adults. J Epidemiol Community Health 71, 381-389.

[3] Yueh B, Shapiro N, MacLean CH, Shekelle PG (2003) Screening and management of adult hearing loss in primary care: Scientific review. J Am Med Assoc 289, 1976-1985.

[4] Vos EM, Greebe P, Visser-Meily JMMA, Rinkel GJE, Vergouwen MDI (2017) Subjective hearing impairment after subarachnoid haemorrhage: Prevalence and risk factors. $J$ Neurol Sci 372, 184-186.

[5] GBD 2017 Disease and Injury Incidence and Prevalence Collaborators (2018) Global, regional, and national incidence, prevalence, and years lived with disability for 354 Diseases and Injuries for 195 countries and territories, 1990-2017: A systematic analysis for the Global Burden of Disease Study 2017. Lancet 392, 1789-1858.

[6] Lin FR, Thorpe R, Gordon-Salant S, Ferrucci L (2011) Hearing loss prevalence and risk factors among older adults in the United States. J Gerontol A Biol Sci Med Sci 66 A, 582-590.

[7] Mick PT, Hämäläinen A, Kolisang L, Kathleen PichoraFuller M, Phillips N, Guthrie D, Wittich W (2021) The prevalence of hearing, vision, and dual sensory loss in older Canadians: An analysis of data from the Canadian Longitudinal Study on Aging. Can J Aging 40, 1-22.

[8] Gates GA, Gibbons LE, McCurry SM, Crane PK, Feeney MP, Larson EB (2010) Executive dysfunction and presbycusis in older persons with and without memory loss and dementia. Cogn Behav Neurol 23, 218-223.

[9] Dubno JR, Eckert MA, Lee FS, Matthews LJ, Schmiedt RA (2013) Classifying human audiometric phenotypes of age-related hearing loss from animal models. J Assoc Res Otolaryngol 14, 687-701.

[10] Kujawa SG, Liberman MC (2015) Synaptopathy in the noise-exposed and aging cochlea: Primary neural degeneration in acquired sensorineural hearing loss. Hear Res 330, 191-199.

[11] Eckert MA, Vaden KI, Dubno JR (2019) Age-related hearing loss associations with changes in brain morphology. Trends Hear 23, 2331216519857267.

[12] Loughrey DG, Kelly ME, Kelley GA, Brennan S, Lawlor BA (2018) Association of age-related hearing loss with cognitive function, cognitive impairment, and dementia a systematic review and meta-analysis. JAMA Otolaryngol Head Neck Surg 144, 115-126.

[13] Taljaard DS, Olaithe M, Brennan-Jones CG, Eikelboom RH, Bucks RS (2016) The relationship between hearing impairment and cognitive function: A meta-analysis in adults. Clin Otolaryngol 41, 718-729.

[14] Pichora-Fuller MK, Alain C, Schneider BA (2017) Older adults at the cocktail party. In The Auditory System at the Cocktail Party, Middlebrooks J, Simon JZ, Popper AN, Fay RR, eds. Springer International Publishing, pp. 227-259.

[15] Pichora-Fuller MK, Kramer SE, Eckert MA, Edwards B, Hornsby BWY, Humes LE, Lemke U, Lunner T, Matthen M, Mackersie CL, Naylor G, Phillips NA, Richter M, Rudner M, Sommers MS, Tremblay KL, Wingfield A (2016) Hearing impairment and cognitive energy: The framework for understanding effortful listening (FUEL). Ear Hear 37 Suppl 1, 5S-27S.

[16] Lin FR, Yaffe K, Xia J, Xue QL, Harris TB, PurchaseHelzner E, Satterfield S, Ayonayon HN, Ferrucci L, Simonsick EM (2013) Hearing loss and cognitive decline in older adults. JAMA Intern Med 173, 293-299.
[17] Golub JS, Brickman AM, Ciarleglio AJ, Schupf N, Luchsinger JA (2020) Association of subclinical hearing loss with cognitive performance. JAMA Otolaryngol Head Neck Surg 146, 57-67.

[18] Deal JA, Betz J, Yaffe K, Harris T, Purchase-Helzner E, Satterfield S, Pratt S, Govil N, Simonsick EM, Lin FR (2017) Hearing impairment and incident dementia and cognitive decline in older adults: The health $\mathrm{ABC}$ study. $J$ Gerontol A Biol Sci Med Sci 72, 703-709.

[19] Giroud N, Pichora-Fuller MK, Mick P, Wittich W, AlYawer F, Rehan S, Orange JB, Phillips NA (2020) Hearing loss is associated with gray matter differences in older adults at risk for and with Alzheimer's disease. medRxiv, 2020.10.07.20208017.

[20] Panza F, Lozupone M, Sardone R, Battista P, Piccininni M, Dibello V, La Montagna M, Stallone R, Venezia P, Liguori A, Giannelli G, Bellomo A, Greco A, Daniele A, Seripa D, Quaranta N, Logroscino G (2019) Sensorial frailty: Age-related hearing loss and the risk of cognitive impairment and dementia in later life. Ther Adv Chronic Dis 10, 2040622318811000.

[21] Gates GA, Anderson ML, McCurry SM, Feeney MP, Larson EB (2011) Central auditory dysfunction as a Harbinger of Alzheimer dementia. Arch Otolaryngol Head Neck Surg 137, 390-395.

[22] Livingston G, Sommerlad A, Orgeta V, Costafreda SG, Huntley J, Ames D, Ballard C, Banerjee S, Burns A, Cohen-Mansfield J, Cooper C, Fox N, Gitlin LN, Howard R, Kales HC, Larson EB, Ritchie K, Rockwood K, Sampson EL, Samus Q, Schneider LS, Selbæk G, Teri L, Mukadam N (2017) Dementia prevention, intervention, and care. Lancet 390, 2673-2734.

[23] Livingston G, Huntley J, Sommerlad A, Ames D, Ballard C, Banerjee S, Brayne C, Burns A, Cohen-Mansfield J, Cooper C, Costafreda SG, Dias A, Fox N, Gitlin LN, Howard R, Kales HC, Kivimäki M, Larson EB, Ogunniyi A, Orgeta V, Ritchie K, Rockwood K, Sampson EL, Samus Q, Schneider LS, Selbæk G, Teri L, Mukadam N (2020) Dementia prevention, intervention, and care: 2020 report of the Lancet Commission. Lancet 396, 413-446.

[24] Le Reste JY, Nabbe P, Manceau B, Lygidakis C, Doerr C, Lingner H, Czachowski S, Munoz M, Argyriadou S, Claveria A, Le Floch B, Barais M, Bower P, Van Marwijk H, Van Royen P, Lietard C (2013) The European General Practice Research Network presents a comprehensive definition of multimorbidity in family medicine and long term care, following a systematic review of relevant literature. J Am Med Dir Assoc 14, 319-325.

[25] Gauld R, Blank R, Burgers J, Cohen AB, Dobrow MK, Ikegami NKI, Kwon S, Luxford K, Milett C, Wendt C (2012) The World Health Report 2008 - Primary healthcare: How wide is the gap between its agenda and implementation in 12 high-income health systems? Healthc Policy 7, 38-58.

[26] Barnett K, Mercer SW, Norbury M, Watt G, Wyke S, Guthrie B (2012) Epidemiology of multimorbidity and implications for health care, research, and medical education: A cross-sectional study. Lancet 380, 37-43.

[27] Kingston A, Robinson L, Booth H, Knapp M, Jagger C, Adelaja B, Avendano M, Bamford SM, Banerjee S, Berwald S, Bowling A, Burgon C, Bustard E, ComasHerrera A, Dangoor M, Dixon J, Farina N, Greengross S, Grundy E, Hu B, King D, Lombard D, Lorenz K, McDaid D, Park A La, Pikhartova J, Rehill A, Wittenberg R (2018) 
Projections of multi-morbidity in the older population in England to 2035: Estimates from the Population Ageing and Care Simulation (PACSim) model. Age Ageing 47, 374-380.

[28] GBD 2013 DALYs and HALE Collaborators, Murray CJ, Barber RM, Foreman KJ, Abbasoglu Ozgoren A, AbdAllah F, Abera SF, Aboyans V, Abraham JP, Abubakar I, Abu-Raddad LJ, et al. (2015) Global, regional, and national disability-adjusted life years (DALYs) for 306 diseases and injuries and healthy life expectancy (HALE) for 188 countries, 1990-2013: Quantifying the epidemiological transition. Lancet 386, 2145-2191.

[29] Ford AH, Hankey GJ, Yeap BB, Golledge J, Flicker L, Almeida OP (2018) Hearing loss and the risk of dementia in later life. Maturitas 112, 1-11.

[30] Kamil RJ, Betz J, Powers BB, Pratt S, Kritchevsky S, Ayonayon HN, Harris TB, Helzner E, Deal JA, Martin K, Peterson M, Satterfield S, Simonsick EM, Lin FR (2016) Association of hearing impairment with incident frailty and falls in older adults. J Aging Health 28, 644-660.

[31] Almeida OP, Ford AH, Hankey GJ, Yeap BB, Golledge J, Flicker L (2019) Hearing loss and incident psychosis in later life: The Health in Men Study (HIMS). Int J Geriatr Psychiatry 34, 408-414.

[32] Tareque MI, Chan A, Saito Y, Ma S, Malhotra R (2019) The impact of self-reported vision and hearing impairment on health expectancy. J Am Geriatr Soc 67, 2528-2536.

[33] Santini ZI, Koyanagi A, Tyrovolas S, Mason C, Haro JM (2015) The association between social relationships and depression: A systematic review. J Affect Disord 175, 53-65.

[34] Kuiper JS, Zuidersma M, Oude Voshaar RC, Zuidema SU, van den Heuvel ER, Stolk RP, Smidt N (2015) Social relationships and risk of dementia: A systematic review and meta-analysis of longitudinal cohort studies. Ageing Res Rev 22, 39-57.

[35] Mick P, Pichora-Fuller MK (2016) Is hearing loss associated with poorer health in older adults who might benefit from hearing screening? Ear Hear 37, e194-e201.

[36] Koller D, Schön G, Schäfer I, Glaeske G, Van Den Bussche H, Hansen H (2014) Multimorbidity and long-term care dependency - A five-year follow-up. BMC Geriatr 14, 70.

[37] Gates GA, Mills JH (2005) Presbycusis. Lancet 366, 11111120.

[38] WHO (2019) Integrated care for older people (ICOPE): Guidance for person-centred assessment and pathways in primary care. World Health Organization, Geneva.

[39] Schow RL, Nerbonne MA (1980) Hearing levels among elderly nursing home residents. J Speech Hear Disord $\mathbf{4 5}$, 124-132.

[40] Weinstein BE (2000) Geriatric audiology, Thieme Medical Publishers, New York.

[41] Burnip LG, Erber NP (1997) Staff knowledge regarding hearing loss and communication among nursing home residents. Aust J Ageing 16, 40-43.

[42] Guthrie DM, Davidson JGS, Williams N, Campos J, Hunter K, Mick P, Orange JB, Pichora-Fuller MK, Phillips NA, Savundranayagam MY, Wittich W (2018) Combined impairments in vision, hearing and cognition are associated with greater levels of functional and communication difficulties than cognitive impairment alone: Analysis of interRAI data for home care and long-term care recipients in Ontario. PLoS One 13, e0192971.
[43] Williams N, Phillips NA, Wittich W, Campos JL, Mick P, Orange JB, Pichora-Fuller MK, Savundranayagam MY, Guthrie DM (2020) Hearing and cognitive impairments increase the risk of long-term care admissions. Innov Aging 4, igz053.

[44] World Health Organization (2021) World Report on Hearing, World Health Organization, Geneva.

[45] American Speech-Language-Hearing Association (2006) Preferred Practice Patterns for the Profession of Audiology.

[46] Ismail Z, Black SE, Camicioli R, Chertkow H, Herrmann N, Laforce R, Montero-Odasso M, Rockwood K, RosaNeto P, Seitz D, Sivananthan S, Smith EE, Soucy JP, Vedel I, Gauthier S (2020) Recommendations of the 5th Canadian Consensus Conference on the diagnosis and treatment of dementia. Alzheimers Dement 16, 1182-1195.

[47] McClannahan KS, Chiu YF, Sommers MS, Peelle JE (2021) Test-retest reliability of audiometric assessment in individuals with mild dementia. JAMA Otolaryngol Head Neck Surg 147, 442-449.

[48] The American Speech-Language-Hearing Association (ASHA) (1997) Guidelines for audiology service delivery in nursing homes [Guidelines]. Retrieved from www.asha.org/policy.

[49] Bott A, Meyer C, Hickson L, Pachana NA (2019) Can adults living with dementia complete pure-tone audiometry? A systematic review. Int J Audiol 58, 185-192.

[50] Hopper T, Hinton P (2012) Hearing loss among individuals with dementia: Barriers and facilitators to care. Can J Speech-Language Pathol Audiol 36, 302-313.

[51] Meyer C, Hickson L (2020) Evidence-based practice guideline: Nursing management of hearing impairment in nursing facility residents. J Gerontol Nurs 46, 15-25.

[52] Adams-Wendling L, Pimple C, Adams S, Titler MG (2008) Nursing management of hearing impairment in nursing facility residents. J Gerontol Nurs 34, 9-17.

[53] McGilton KS, Bowers BJ, Heath H, Shannon K, Dellefield ME, Prentice D, Siegel EO, Meyer J, Chu CH, Ploeg J, Boscart VM, Corazzini KN, Anderson RA, Mueller CA (2016) Recommendations from the international consortium on professional nursing practice in long-term care homes. J Am Med Dir Assoc 17, 99-103.

[54] Hubbard HI, Mamo SK, Hopper T (2018) Dementia and hearing loss: Interrelationships and treatment considerations. Semin Speech Lang 39, 197-210.

[55] WHO (2019) Risk Reduction of Cognitive Decline And Dementia, World Health Organization, Geneva.

[56] Macphee GJA, Crowther JA, Mcalpine CH (1988) A simple screening test for hearing impairment in elderly patients. Age Ageing 17, 347-351.

[57] Torres-Russotto D, Landau WM, Harding GW, Bohne BA, Sun K, Sinatra PM (2009) Calibrated finger rub auditory screening test (CALFRAST). Neurology 72, 1595-1600.

[58] Strawbridge WJ, Wallhagen MI (2017) Simple tests compare well with a hand-held audiometer for hearing loss screening in primary care. J Am Geriatr Soc 65, 22822284.

[59] Maguire N, Prosser S, Boland R, McDonnell A (1998) Screening for hearing loss in general practice using a questionnaire and the whisper test. Eur J Gen Pract 4, 18-21.

[60] Vita L, Bruno D (2021) The challenge of detecting cognitive impairment in hearing-impaired individuals. Eur $J$ Neurol 28, 1795-1796. 
[61] Pittman CA, Ward BK, Nieman CL (2021) A review of adult-onset hearing loss: A primer for neurologists. Curr Treat Options Neurol 23, 20.

[62] Mamo SK, Oh E, Lin FR (2017) Enhancing communication in adults with dementia and age-related hearing loss. Semin Hear 38, 177-183.

[63] McGilton KS, Rochon E, Sidani S, Shaw A, Ben-David BM, Saragosa M, Boscart VM, Wilson R, GalimidiEpstein KK, Pichora-Fuller MK (2017) Can we help care providers communicate more effectively with persons having dementia living in long-term care homes? Am $J$ Alzheimers Dis Other Demen 32, 41-50.

[64] Dupuis K, Yusupov I, Vandermorris S, Murphy KL, Rewilak D, Stokes KA, Reed M (2019) Considering age-related hearing loss in neuropsychological practice: Findings from a feasibility study. Can J Aging 38, 245-252.

[65] Hill-Briggs F, Dial JG, Morere DA, Joyce A (2007) Neuropsychological assessment of persons with physical disability, visual impairment or blindness, and hearing impairment or deafness. Arch Clin Neuropsychol 22, 389404.

[66] Al-Yawer F, Pichora-Fuller MK, Phillips NA (2019) The Montreal Cognitive Assessment after omission of hearing-dependent subtests: Psychometrics and clinical recommendations. J Am Geriatr Soc 67, 1689-1694.

[67] Dupuis K, Pichora-Fuller MK, Chasteen AL, Marchuk V, Singh G, Smith SL (2015) Effects of hearing and vision impairments on the Montreal Cognitive Assessment. Aging, Neuropsychol Cogn 22, 413-437.

[68] Hutchinson AM, Milke DL, Maisey S, Johnson C, Squires JE, Teare G, Estabrooks CA (2010) The resident assessment instrument-minimum data set 2.0 quality indicators: A systematic review. BMC Health Serv Res 10, 1-14.

[69] Zimmerman DR, Karon SL, Arling G, Clark BR, Collins T, Ross R, Sainfort F (1995) Development and testing of nursing home quality indicators. Health Care Financ Rev 16, 107-127.

[70] Hopper T, Slaughter SE, Hodgetts B, Ostevik A, Ickert C (2016) Hearing loss and cognitive-communication test performance of long-term care residents with dementia: Effects of amplification. J Speech, Lang Hear Res 59, 1533-1542.

[71] Morris JN, Jones RN, Fries BE, Hirdes JP (2004) Convergent validity of minimum data set-based performance quality indicators in postacute care settings. Am J Med Qual 19, 242-247.

[72] Hopper T, Bayles KA, Harris FP, Holland A (2001) The relationship between minimum data set ratings and scores on measures of communication and hearing among nursing home residents with dementia. Am J Speech Language Pathol 10, 370-381.

[73] Bainbridge KE, Wallhagen MI (2014) Hearing loss in an aging American population: Extent, impact, and management. Annu Rev Public Health 35, 139-152.

[74] Kiely KM, Gopinath B, Mitchell P, Browning CJ, Anstey KJ (2012) Evaluating a dichotomized measure of selfreported hearing loss against gold standard audiometry: Prevalence estimates and age bias in a pooled national data set. J Aging Health 24, 439-458.

[75] Everett A, Wong A, Piper R, Cone B, Marrone N (2020) Sensitivity and specificity of pure-tone and subjective hearing screenings using Spanish-language questions. Am J Audiol 29, 35-49.

[76] Garahan MB, Waller JA, Houghton M, Tisdale WA, Runge CF (1992) Hearing loss prevalence and manage- ment in nursing home residents. J Am Geriatr Soc 40, 130134.

[77] Cohen-Mansfield J, Taylor JW (2004) Hearing aid use in nursing homes, part 1: Prevalence rates of hearing impairment and hearing aid use. J Am Med Dir Assoc 5, 283288.

[78] Ray M, Dening T, Crosbie B (2019) Dementia and hearing loss: A narrative review. Maturitas 128, 64-69.

[79] McCreedy EM, Weinstein BE, Chodosh J, Blustein J (2018) Hearing loss: Why does it matter for nursing homes? J Am Med Dir Assoc 19, 323-327.

[80] Punch R, Horstmanshof L (2019) Hearing loss and its impact on residents in long term care facilities: A systematic review of literature. Geriatr Nurs (Minneap) 40, 138-147.

[81] Höbler F, Argueta-Warden X, Rodríguez-Monforte M, Escrig-Pinol A, Wittich W, McGilton KS (2018) Exploring the sensory screening experiences of nurses working in long-term care homes with residents who have dementia: A qualitative study. BMC Geriatr 18, 1-14.

[82] McGilton KS, Höbler F, Campos J, Dupuis K, Labreche T, Guthrie DM, Jarry J, Singh G, Wittich W (2016) Hearing and vision screening tools for long-term care residents with dementia: Protocol for a scoping review. BMJ Open 6, e011945.

[83] Campos JL, Höbler F, Bitton E, Labreche T, McGilton KS, Wittich W (2019) Screening for vision impairments in individuals with dementia living in long-term care: A scoping review. J Alzheimers Dis 68, 1039-1049.

[84] Arksey H, O'Malley L (2005) Scoping studies: Towards a methodological framework. Int J Soc Res Methodol Theory Pract 8, 19-32.

[85] Peters MDJ, Godfrey CM, Khalil H, McInerney P, Parker D, Soares CB (2015) Guidance for conducting systematic scoping reviews. Int J Evid Based Healthc 13, 141-146.

[86] Yeung E, Woods N, Dubrowski A, Hodges B, Carnahan $\mathrm{H}$ (2015) Sensibility of a new instrument to assess clinical reasoning in post-graduate orthopaedic manual physical therapy education. Man Ther 20, 303-312.

[87] Feinstein AR (1987) The theory and evaluation of sensibility. In Clinimetrics, Feinstein AR, ed. Murray Printing Company, Westford, MS, pp. 141-166.

[88] Hirose T, Hasegawa J, Izawa S, Enoki H, Suzuki Y, Kuzuya M (2014) Accumulation of geriatric conditions is associated with poor nutritional status in dependent older people living in the community and in nursing homes. Geriatr Gerontol Int 14, 198-205.

[89] Ives DG, Bonino P, Traven ND, MD LHK (1995) Characteristics and comorbidities of rural older adults with hearing impairment. J Am Geriatr Soc 43, 803-806.

[90] Vaughan RM, McGee C, Guerin S, Tyrrell J, Dodd P (2016) The challenges of diagnosis and treatment of dementia in down's syndrome. Ir J Psychol Med 33, 151-158.

[91] Karlsson S, Nyberg L, Sandman PO (1997) The use of physical restraints in elder care in relation to fall risk. Scand J Caring Sci 11, 238-242.

[92] Karlsson S, Bucht G, Eriksson S, Sandman PO (1996) Physical restraints in geriatric care in Sweden: Prevalence and patient characteristics. J Am Geriatr Soc 44, 13481354.

[93] Andersen-Ranberg K, Schroll M, Jeune B (2001) Healthy centenarians do not exist, but autonomous centenarians do: A population-based study of morbidity among danish centenarians. J Am Geriatr Soc 49, 900-908. 
[94] Formiga F, Ferrer A, Duaso E (2006) Evaluación de las caídas en las personas mayores de 89 años institucionalizadas. Estudio NonaSantfeliu. Rev Esp Geriatr Gerontol 41, 138-141.

[95] Wang N, Yang H, Su J, Kong F, Zhang M, Yan B, Dong H, Zhang X, Jia J, Han D (2003) [Hearing impairment in senile dementia of Alzheimer's type]. Zhonghua Er Bi Yan Hou Ke Za Zhi 38, 198-201.

[96] Ferrer Feliu A, Formiga F, Henríquez E, Lombarte Bonfill I, Olmedo C, Pujol Farriols R (2006) Functional and cognitive assessment in an urban population older than 89 years: The NonaSantFeliu study. Rev Esp Geriatr Gerontol 41, 21-26.

[97] Formiga F, Ferrer A, Pérez-Castejón JM, Olmedo C, Henríquez E, Pujol R (2006) Relación entre la pérdida sensorial y la capacidad funcional en personas mayores de 89 años. Estudio NonaSantfeliu. Rev Esp Geriatr Gerontol 41, 258-263.

[98] Formiga F, Ferrer A, Duaso E, Olmedo C, Pujol R (2008) Falls in nonagenarians after 1-year of follow-up: The NonaSantfeliu study. Arch Gerontol Geriatr 46, 15-23.

[99] Yoro-Zohoun I, Nubukpo P, Houinato D, Mbelesso P, Ndamba-Bandzouzi B, Clément JP, Dartigues JF, Preux PM, Guerchet M (2019) Neuropsychiatric symptoms among older adults living in two countries in Central Africa (EPIDEMCA study). Int J Geriatr Psychiatry 34, 169-178.

[100] Ajay S, Kasthuri A, Kiran P, Malhotra R (2017) Association of impairments of older persons with caregiver burden among family caregivers: Findings from rural South India. Arch Gerontol Geriatr 68, 143-148.

[101] Kamitani H, Umegaki H, Okamoto K, Kanda S, Asai A, Maeda K, Nomura H, Shimojima T, Suzuki Y, Ohshima H, Kuzuya M (2017) Development and validation of a new quality of life scale for patients receiving homebased medical care: The Observational Study of Nagoya Elderly with Home Medical Care. Geriatr Gerontol Int 17, 440-448.

[102] Sachdev PS, Levitan C, Crawford J, Sidhu M, Slavin M, Richmond R, Kochan N, Brodaty H, Wen W, Kang K, Mather KA (2013) The Sydney Centenarian Study: Methodology and profile of centenarians and nearcentenarians. Int Psychogeriatr 25, 993-1005.

[103] Duba AS, Rajkumar AP, Prince M, Jacob KS (2012) Determinants of disability among the elderly population in a rural south Indian community: The need to study local issues and contexts. Int Psychogeriatr 24, 333-341.

[104] Pérès K, Matharan F, Allard M, Amieva H, Baldi I, Barberger-Gateau P, Bergua V, Bourdel-Marchasson I, Delcourt C, Foubert-Samier A, Fourrier-Réglat A, Gaimard M, Laberon S, Maubaret C, Postal V, Chantal C, Rainfray M, Rascle N, Dartigues JF (2012) Health and aging in elderly farmers: The AMI cohort. BMC Public Health 12, 558.

[105] Prince M, Acosta D, Ferri CP, Guerra M, Huang Y, Jacob KS, Jotheeswaran AT, Liu Z, Llibre Rodriguez JJ, Salas A, Sosa AL, Williams JD (2011) The association between common physical impairments and dementia in low and middle income countries, and, among people with dementia, their association with cognitive function and disability. A 10/66 Dementia Research Group populationbased study. Int J Geriatr Psychiatry 26, 511-519.

[106] Miranda-Castillo C, Woods B, Orrell M (2010) People with dementia living alone: What are their needs and what kind of support are they receiving? Int Psychogeriatr 22, 607-617.

[107] Ng TP, Feng L, Chiam PC, Kua EH (2006) Psychiatric morbidity and acute hospitalization in elderly people. Int Psychogeriatr 18, 701-711.

[108] Palmer CV, Adams SW, Bourgeois M, Durrant J, Rossi M (1999) Reduction in caregiver-identified problem behaviors in patients with Alzheimer disease post-hearing-aid fitting. J Speech Lang Hear Res 42, 312-328.

[109] Palmer C V., Adams SW, Durrant JD, Bourgeois M, Rossi M (1998) Managing hearing loss in a patient with Alzheimer disease. J Am Acad Audiol 9, 275-284.

[110] Østbye T, Steenhuis R, Wolfson C, Walton R, Hill G (1999) Predictors of five-year mortality in older Canadians: The Canadian study of health and aging. J Am Geriatr Soc 47, 1249-1254.

[111] Kiely KM, Mortby ME, Anstey KJ (2018) Differential associations between sensory loss and neuropsychiatric symptoms in adults with and without a neurocognitive disorder. Int Psychogeriatr 30, 261-272.

[112] Neff RM, Jicha G, Westgate PM, Hawk GS, Bush ML, McNulty B (2019) Neuropathological findings of dementia associated with subjective hearing loss. Otol Neurotol 40, E883-E893.

[113] Sugiura S, Yasue M, Sakurai T, Sumigaki C, Uchida Y, Nakashima T, Toba K (2014) Effect of cerumen impaction on hearing and cognitive functions in Japanese older adults with cognitive impairment. Geriatr Gerontol Int 14, 56-61.

[114] Ghiringhelli R, Iorio MCM (2013) Hearing aids and recovery times: A study according to cognitive status. Braz J Otorhinolaryngol 79, 177-184.

[115] Hutchison B, Covan EK, Bogus JC (2012) Presbycusis, part 1: Can you hear the music of life? Care Manag J 13, $148-172$.

[116] Mahoney CJ, Rohrer JD, Goll JC, Fox NC, Rossor MN, Warren JD (2011) Structural neuroanatomy of tinnitus and hyperacusis in semantic dementia. J Neurol Neurosurg Psychiatry 82, 1274-1278.

[117] Han JH, Morandi A, Ely EW, Callison C, Zhou C, Storrow AB, Dittus RS, Habermann R, Schnelle J (2009) Delirium in the nursing home patients seen in the emergency department: Brief reports. J Am Geriatr Soc 57, 889894.

[118] Han JH, Zimmerman EE, Cutler N, Schnelle J, Morandi A, Dittus RS, Storrow AB, Ely EW (2009) Delirium in older emergency department patients: Recognition, risk factors, and psychomotor subtypes. Acad Emerg Med 16, 193-200.

[119] De Silva ML, McLaughlin MT, Rodrigues EJ, Broadbent JC, Gray AR, Hammond-Tooke GD (2008) A MiniMental Status Examination for the hearing impaired. Age Ageing 37, 593-595.

[120] Wang NY, Yang HJ, Su JF, Kong F, Zhang MX, Yan B, Dong HQ, Zhang XQ, Jia JP, Han DM (2007) Hearing impairment in senile dementia of Alzheimer's type. J Otol 2, 14-17.

[121] Allen NH, Burns A, Newton V, Hickson F, Ramsden R, Rogers J, Butler S, Thistlewaite G, Morris J (2003) The effects of improving hearing in dementia. Age Ageing 32, 189-193.

[122] Galanakis P, Bickel H, Gradinger R, Von Gumppenberg S, Förstl H (2001) Acute confusional state in the elderly following hip surgery: Incidence, risk factors and complications. Int J Geriatr Psychiatry 16, 349-355. 
[123] Gold M, Lightfoot LA, Hnath-Chisolm T (1996) Hearing loss in a memory disorders clinic: A specially vulnerable population. Arch Neurol 53, 922-928.

[124] Robinson S, Rich C, Weitzel T, Vollmer C, Eden B (2008) Delirium prevention for cognitive, sensory, and mobility impairments. Res Theory Nurs Pract 22, 103-113.

[125] Cimarolli VR, Jopp DS (2014) Sensory impairments and their associations with functional disability in a sample of the oldest-old. Qual Life Res 23, 1977-1984.

[126] Teipel S, Fritze T, Ovari A, Buhr A, Kilimann I, Witt G, Pau HW, Doblhammer G (2015) Regional pattern of dementia and prevalence of hearing impairment in Germany. $J \mathrm{Am}$ Geriatr Soc 63, 1527-1533.

[127] Hazra NC, Dregan A, Jackson S, Gulliford MC (2015) Differences in health at age 100 according to sex: Population-based cohort study of centenarians using electronic health records. J Am Geriatr Soc 63, 1331-1337.

[128] Wen YH, Wu SS, Lin CHR, Tsai JH, Yang P, Chang YP, Tseng KH (2016) A Bayesian approach to identifying new risk factors for dementia. Medicine (Baltimore) 95, e3658.

[129] Eichler K, Scrabal C, Steurer J, Mann E (2007) Preventive health risk appraisal for older people and impact on GPs' patient management: A prospective study. Fam Pract 24, 604-609.

[130] Deardorff WJ, Liu PL, Sloane R, Van Houtven C, Pieper CF, Hastings SN, Cohen HJ, Whitson HE (2019) Association of sensory and cognitive impairment with healthcare utilization and cost in older adults. J Am Geriatr Soc 67, 1617-1624.

[131] Villeneuve A, Hommet C, Aussedat C, Lescanne E, Reffet K, Bakhos D (2017) Audiometric evaluation in patients with Alzheimer's disease. EurArch Otorhinolaryngol 274, 151-157.

[132] Nguyen MF, Bonnefoy M, Adrait A, Gueugnon M, Petitot C, Collet L, Roux A, Perrot X (2017) Efficacy of hearing AIDS on the cognitive status of patients with Alzheimer's disease and hearing loss: A multicenter controlled randomized trial. J Alzheimers Dis 58, 123-137.

[133] Heward J, Stone L, Paddick SM, Mkenda S, Gray WK, Dotchin CL, Kissima J, Collingwood C, Swai B, Walker RW (2018) A longitudinal study of cognitive decline in rural Tanzania: Rates and potentially modifiable risk factors. Int Psychogeriatr 30, 1333-1343.

[134] Guzon-Illescas O, Perez Fernandez E, Crespí Villarias N, Quirós Donate FJ, Peña M, Alonso-Blas C, García-Vadillo A, Mazzucchelli R (2019) Mortality after osteoporotic hip fracture: Incidence, trends, and associated factors. $J$ Orthop Surg Res 14, 203.

[135] Adrait A, Perrot X, Nguyen MF, Gueugnon M, Petitot C, Collet L, Roux A, Bonnefoy M (2017) Do hearing aids influence behavioral and psychological symptoms of dementia and quality of life in hearing impaired Alzheimer's disease patients and their caregivers? $J$ Alzheimers Dis 58, 109-121.

[136] Pentzek M, Wollny A, Wiese B, Jessen F, Haller F, Maier W, Riedel-Heller SG, Angermeyer MC, Bickel H, Mösch E, Weyerer S, Werle J, Bachmann C, Zimmermann T, Van Den Bussche H, Abholz HH, Fuchs A (2009) Apart from nihilism and stigma: What influences general practitioners' accuracy in identifying incident dementia? Am J Geriatr Psychiatry 17, 965-975.

[137] Luzzi S, Baldinelli S, Ranaldi V, Fabi K, Cafazzo V, Fringuelli F, Silvestrini M, Provinciali L, Reverberi C, Gainotti G (2017) Famous faces and voices: Differential profiles in early right and left semantic demen- tia and in Alzheimer's disease. Neuropsychologia 94, $118-128$.

[138] Golden EC, Josephs KA (2015) Minds on replay: Musical hallucinations and their relationship to neurological disease. Brain 138, 3793-3802.

[139] Grue EV, Kirkevold M, Ranhoff AH (2009) Prevalence of vision, hearing, and combined vision and hearing impairments in patients with hip fractures. J Clin Nurs 18, 3037-3049.

[140] Grue EV, Kirkevold M, Mowinchel P, Ranhoff AH (2009) Sensory impairment in hip-fracture patients 65 years or older and effects of hearing/vision interventions on fall frequency. $J$ Multidiscip Healthc 2, 1-11.

[141] Sri-On J, Tirrell GP, Vanichkulbodee A, Niruntarai S, Liu SW (2016) The prevalence, risk factors and short-term outcomes of delirium in Thai elderly emergency department patients. Emerg Med J 33, 17-22.

[142] Gyanwali B, Hilal S, Venketasubramanian N, Chen C, Loo JHY (2020) Hearing handicap in Asian patients with dementia. Am J Otolaryngol 41, 102377.

[143] Nirmalasari O, Mamo SK, Nieman CL, Simpson A, Zimmerman J, Nowrangi MA, Lin FR, Oh ES (2017) Age-related hearing loss in older adults with cognitive impairment. Int Psychogeriatr 29, 115-121.

[144] Ouchi Y, Meguro K, Akanuma K, Kato Y, Yamaguchi S (2015) Normal hearing ability but impaired auditory selective attention associated with prediction of response to donepezil in patients with Alzheimer's disease. Behav Neurol 2015, 540348.

[145] Riello R, Geroldi C, Zanetti O, Vergani C, Frisoni GB (2004) Differential associations of Head and Body Symptoms with depression and physical comorbidity in patients with cognitive impairment. Int J Geriatr Psychiatry 19, 209-215.

[146] Devanand DP, Lee S, Manly J, Andrews H, Schupf N, Masurkar A, Stern Y, Mayeux R, Doty RL (2015) Olfactory identification deficits and increased mortality in the community. Ann Neurol 78, 401-411.

[147] Millán-Calenti JC, Tubío J, Pita-Fernández S, GonzálezAbraldes I, Lorenzo T, Maseda A (2009) Prevalence of cognitive impairment: effects of level of education, age, sex and associated factors. Dement Geriatr Cogn Disord 28, 455-460.

[148] Formiga F, Navarro M, Duaso E, Chivite D, Ruiz D, Perez-Castejon JM, Lopez-Soto A, Pujol R (2008) Factors associated with hip fracture-related falls among patients with a history of recurrent falling. Bone 43, 941-944.

[149] Unsworth C, Chan SP (2016) Determining fitness to drive among drivers with Alzheimer's disease or cognitive decline. Br J Occup Ther 79, 102-110.

[150] Quaranta N, Coppola F, Casulli M, Barulli O, Lanza F, Tortelli R, Capozzo R, Leo A, Tursi M, Grasso A, Solfrizzi V, Sobbà C, Logroscino G (2014) The prevalence of peripheral and central hearing impairment and its relation to cognition in older adults. Audiol Neurootol 19 Suppl 1, $10-14$.

[151] Strouse AL, Hall JW, Burger MC (1995) Central auditory processing in Alzheimer's disease. Ear Hear 16, 230-238.

[152] Williams N, Guthrie DM, Davidson JGS, Fisher K, Griffith LE (2020) A deterioration in hearing is associated with functional and cognitive impairments, difficulty with communication, and greater health instability. J Appl Gerontol 39, 159-171.

[153] Davidson JGS, Guthrie DM (2019) Older adults with a combination of vision and hearing impairment expe- 
rience higher rates of cognitive impairment, functional dependence, and worse outcomes across a set of quality indicators. J Aging Health 31, 85-108.

[154] Ibrahim AA, AI-Lami F, Al-Rudainy R, Khader YS (2019) Mental disorders among elderly people in Baghdad, Iraq, 2017. Inquiry 56, 46958019845960.

[155] Schonfeld E, Meyer LT, Becker A, Tate K, Moodabagil M, McSharry C, Amidi M, Bestler A, Senno RG (2018) Correlation of hearing loss and chronic falling among patients with dementia in 3 memory-care communities. Ann LongTerm Care 26, 21-25.

[156] Hsu TJ, Tsai H Te, Hwang AC, Chen LY, Chen LK (2017) Predictors of non-pharmacological intervention effect on cognitive function and behavioral and psychological symptoms of older people with dementia. Geriatr Gerontol Int 17, 28-35.

[157] Jupiter (2016) Does hearing assistive technology provide benefit to nursing home residents with dementia? A pilot study. J Acad Rehabil Audiol 49, 34-39.

[158] García De Yébenes MJ, Otero A, Zunzunegui MV, Rodríguez-Laso A, Sánchez-Sánchez F, Del Ser T (2003) Validation of a short cognitive tool for the screening of dementia in elderly people with low educational level. Int J Geriatr Psychiatry 18, 925-936.

[159] Szczerbińska K, Topinková E, Brzyski P, van der Roest HG, Richter T, Finne-Soveri H, Denkinger MD, Gindin J, Onder G, Bernabei R (2016) Delivery of care to nursing home residents with diabetes: Results from the SHELTER Study. J Am Med Dir Assoc 17, 807-813.

[160] Yamada Y, Denkinger MD, Onder G, Van Der Roest HG, Finne-Soveri H, Bernabei R, Topinkova E (2016) Joint associations of dual sensory impairment and no-activity involvement with 1-year mortality in nursing homes: Results from the SHELTER Study. J Gerontol A Biol Sci Med Sci 71, 643-648.

[161] Yamada Y, Denkinger MD, Onder G, Henrard JC, Van Der Roest HG, Finne-Soveri H, Richter T, Vlachova M, Bernabei R, Topinkova E (2015) Dual sensory impairment and cognitive decline: The results from the Shelter Study. J Gerontol A Biol Sci Med Sci 71, 117-123.

[162] Yamada Y, Denkinger MD, Onder G, Finne-Soveri H, van der Roest H, Vlachova M, Richter T, Gindin J, Bernabei R, Topinkova E (2015) Impact of dual sensory impairment on onset of behavioral symptoms in european nursing homes: results from the services and health for elderly in long-term care study. J Am Med Dir Assoc 16, 329-333.

[163] Yamada Y, Vlachova M, Richter T, Finne-Soveri H, Gindin $\mathrm{J}$, van der Roest H, Denkinger MD, Bernabei R, Onder G, Topinkova E (2014) Prevalence and correlates of hearing and visual impairments in European nursing homes: Results from the SHELTER Study. J Am Med Dir Assoc 15, 738-743.

[164] Boorsma M, Joling K, Dussel M, Ribbe M, Frijters D, Van Marwijk HWJ, Nijpels G, Van Hout H (2012) The incidence of depression and its risk factors in dutch nursing homes and residential care homes. Am J Geriatr Psychiatry 20, 932-942.

[165] Jupiter T (2012) Cognition and screening for hearing loss in nursing home residents. $J$ Am Med Dir Assoc 13, 744-747.

[166] Ishii S, Streim JE, Saliba D (2010) Potentially reversible resident factors associated with rejection of care behaviors. J Am Geriatr Soc 58, 1693-1700.

[167] Cohen-Mansfield J, Marx MS, Regier NG, Dakheel-Ali M (2009) The impact of personal characteristics on engage- ment in nursing home residents with dementia. Int $J$ Geriatr Psychiatry 24, 755-763.

[168] Damián J, Pastor-Barriuso R, Valderrama-Gama E (2008) Factors associated with self-rated health in older people living in institutions. BMC Geriatr 8, 5 .

[169] Leroi I, Simkin Z, Hooper E, Wolski L, Abrams H, Armitage CJ, Camacho E, Charalambous AP, Collin F, Constantinidou F, Dawes P, Elliott R, Falkingham S, Frison E, Hann M, Helmer C, Himmelsbach I, Hussain H, Marié S, Montecelo S, Thodi C, Yeung WK (2020) Impact of an intervention to support hearing and vision in dementia: The SENSE-Cog Field Trial. Int J Geriatr Psychiatry 35, 348-357.

[170] Orrell M, Hancock GA, Liyanage KCG, Woods B, Challis D, Hoe J (2008) The needs of people with dementia in care homes: The perspectives of users, staff and family caregivers. Int Psychogeriatr 20, 941-951.

[171] Brink P, Stones M (2007) Examination of the relationship among hearing impairment, linguistic communication, mood, and social engagement of residents in complex continuing-care facilities. Gerontologist 47, 633-641.

[172] Looi V, Hickson L, Price A, Lee G, Mokoka A, Worrall L, Wilson J, Tilse C (2004) Audiological rehabilitation in a residential aged care facility. Aust New Zeal J Audiol 26, 12-29.

[173] Cacchione PZ, Culp K, Dyck MJ, Laing J (2003) Risk for acute confusion in sensory-impaired, rural, long-term-care elders. Clin Nurs Res 12, 340-355.

[174] Zimmerman S, Scott AC, Park NS, Hall SA, Wetherby MM, Gruber-Baldini AL, Morgan LA (2003) Social engagement and its relationship to service provision in residential care and assisted living. Soc Work Res 27, 6-18.

[175] Mann AH, Schneider J, Mozley CG, Levin E, Blizard R, Netten A, Kharicha K, Egelstaff R, Abbey A, Todd C (2000) Depression and the response of residential homes to physical health needs. Int J Geriatr Psychiatry 15, 11051112.

[176] Gambassi G, Landi F, Lapane KL, Sgadari A, Mor V, Bernabei R (1999) Predictors of mortality in patients with Alzheimer's disease living in nursing homes. $J$ Neurol Neurosurg Psychiatry 67, 59-65.

[177] Sloane PD, Davidson S, Knight N, Tangen C, Mitchell CM (1999) Severe disruptive vocalizers. J Am Geriatr Soc 47, 439-445.

[178] Resnick HE, Fries BE, Verbrugge LM (1997) Windows to their world: The effect of sensory impairments on social engagement and activity time in nursing home residents. J Gerontol B Psychol Sci Soc Sci 52, 135-144.

[179] Hort-Legrand C, Hervy MP, Farah S, Metral S (1996) Early auditory evoked potentials during the dementia syndrome: Comparative study of brain-stem early auditory evoked potentials as a function of the physiopathology of dementia syndromes in an elderly institutionalized population | Potentiels évoqués aud. Rev Geriatr 21, 251-258.

[180] Liang CK, Chou MY, Chen LY, Wang KY, Lin SY, Chen LK, Lin Y Te, Liu TY, Loh CH (2017) Delaying cognitive and physical decline through multidomain interventions for residents with mild-to-moderate dementia in dementia care units in Taiwan: A prospective cohort study. Geriatr Gerontol Int 17, 36-43.

[181] Littbrand H, Carlsson M, Lundin-Olsson L, Lindelöf N, Håglin L, Gustafson Y, Rosendahl E (2011) Effect of a high-intensity functional exercise program on functional balance: Preplanned subgroup analyses of a randomized 
controlled trial in residential care facilities. J Am Geriatr Soc 59, 1274-1282.

[182] Smith K, Flicker L, Dwyer A, Atkinson D, Almeida OP, Lautenschlager NT, Logiudice D (2010) Factors associated with dementia in Aboriginal Australians. Aust N Z J Psychiatry 44, 888-893.

[183] Vance DE, Burgio LD, Roth DL, Stevens AB, Fairchild JK, Yurick A (2003) Predictors of agitation in nursing home residents. J Gerontol B Psychol Sci Soc Sci 58, 129-137.

[184] Jin EHC, Yap PLK, Au LSY, Ang YH, Ee CH (2003) Article: Who are the residents of a nursing home in Singapore? [1] (multiple letters). Singapore Med J 44, 428-429.

[185] Cimarolli VR, Jung S (2016) Intensity of occupational therapy utilization in nursing home residents: The role of sensory impairments. J Am Med Dir Assoc 17, 939-942.

[186] Davies HR, Cadar D, Herbert A, Orrell M, Steptoe A (2017) Hearing impairment and incident dementia: Findings from the English Longitudinal Study of Ageing. $\mathrm{J} \mathrm{Am}$ Geriatr Soc 65, 2074-2081.

[187] Heywood R, Gao Q, Nyunt MSZ, Feng L, Chong MS, Lim WS, Yap P, Lee T-S, Yap KB, Wee SL, Ng TP (2017) Hearing loss and risk of mild cognitive impairment and dementia: Findings from the Singapore Longitudinal Ageing Study. Dement Geriatr Cogn Disord 43, 259-268.

[188] Ojagbemi A, Bello T, Luo Z, Gureje O (2017) Chronic conditions, new onset, and persistent disability in the Ibadan Study of Aging. J Gerontol A Biol Sci Med Sci 72, 9971005.

[189] Smith AK, Ritchie CS, Miao Y, Boscardin WJ, Wallhagen ML (2016) Self-reported hearing in the last 2 years of life in older adults. J Am Geriatr Soc 64, 1486-1491.

[190] De Carvalho IAM, Mansur LL (2008) Validation of ASHA FACS-functional assessment of communication skills for Alzheimer disease population. Alzheimer Dis Assoc Disord 22, 375-381.

[191] Gimeno Vilar C, Cervera Paz FJ (2010) Enfermedad de Alzheimer y pérdida auditiva. Rev Neurol 50, 65-71.

[192] Kurita A, Murakami M, Takagi S, Matsushima M, Suzuki M (2010) Visual hallucinations and altered visual information processing in Parkinson disease and dementia with Lewy bodies. Mov Disord 25, 167-171.

[193] Caravaglios G, Costanzo E, Palermo F, Muscoso EG (2008) Decreased amplitude of auditory event-related delta responses in Alzheimer's disease. Int J Psychophysiol 70, 23-32.

[194] Gootjes L, Bouma A, Van Strien JW, Schijndel R Van, Barkhof F, Scheltens P (2006) Corpus callosum size correlates with asymmetric performance on a dichotic listening task in healthy aging but not in Alzheimer's disease. Neuropsychologia 44, 208-217.

[195] Voyer P, Cole MG, McCusker J, Belzile É (2005) Characteristics of institutionalized older patients with delirium newly admitted to an acute care hospital. Clin Eff Nurs $\mathbf{9}$, $13-25$.

[196] Kaga K, Nakamura M, Takayama Y, Momose H (2004) A case of cortical deafness and anarthria. Acta Otolaryngol 124, 202-205.

[197] Boelen HJJ, Veen C (1999) Possibilities in improvement of speech understanding for patients with Alzheimer's disease. Tijdschr Gerontol Geriatr 30, 164-167.

[198] Marshall NB, Duke LW, Walley AC (1996) Effects of age and Alzheimer's disease on recognition of gated spoken words. J Speech Lang Hear Res 39, 724-733.
[199] Gates GA, Karzon RK, Garcia P, Peterein J, Morris JC, Storandt M, Miller JP (1995) Auditory dysfunction in aging and senile dementia of the Alzheimer's type. Arch Neurol 52, 626-634.

[200] Shahmiri E, Jafari Z, Noroozian M, Zendehbad A, Niri HH, Yoonessi A (2017) Effect of mild cognitive impairment and Alzheimer disease on auditory steady-state responses. Basic Clin Neurosci 8, 299-306.

[201] Schaub RT, Münzberg H, Borchelt M, Nieczaj R, Hillen T, Reischies FM, Schlattmann P, Geiselmann B, SteinhagenThiessen E (2000) Ventilatory capacity and risk for dementia. J Gerontol A Biol Sci Med Sci 55, M677M683.

[202] Huh MJ (2018) The relationships between cognitive function and hearing loss among the elderly. $J$ Phys Ther Sci 30, 174-176.

[203] Luo Y, He P, Guo C, Chen G, Li N, Zheng X (2018) Association between sensory impairment and dementia in older adults: Evidence from China. J Am Geriatr Soc 66, 480-486.

[204] Gallacher J, Ilubaera V, Ben-Shlomo Y, Bayer A, Fish M, Babisch W, Elwood P (2012) Auditory threshold, phonologic demand, and incident dementia. Neurology 79, 1583-1590.

[205] Akyiğit A, Subaşi B, Sakallioğlu Ö, Polat C, Düzer S, Keleş E, Özer N (2014) Hearing levels in patients with Alzheimer's dementia. Turk Geriatr Derg 17, 285-289.

[206] Eichhorn S, Hesse G, Laubert A (2014) Detection of hearing loss in dementia patients: Pilot study and literature survey. HNO 62, 800-805.

[207] Cintra MTG, Ávila RT, Soares TO, Cunha LCM, Silveira KD, de Moraes EN, Simas KR, Fernandes RB, Gonçalves DU, de Rezende NA, Bicalho MAC (2018) Increased N200 and P300 latencies in cognitively impaired elderly carrying ApoE $\varepsilon-4$ allele. Int J Geriatr Psychiatry 33, e221-e227.

[208] Hardy CJD, Agustus JL, Marshall CR, Clark CN, Russell LL, Bond RL, Brotherhood E V., Thomas DL, Crutch SJ, Rohrer JD, Warren JD (2017) Behavioural and neuroanatomical correlates of auditory speech analysis in primary progressive aphasias. Alzheimers Res Ther 9, $1-10$.

[209] Lin PH, Chen HH, Chen NC, Chang WN, Huang CW, Chang YT, Hsu SW, Hsu CW, Chang CC (2016) Anatomical correlates of non-verbal perception in dementia patients. Front Aging Neurosci 8, 207.

[210] Idrizbegovic E, Hederstierna C, Rosenhall U (2016) Mismatch negativity and ear laterality in Alzheimer's disease and in mild cognitive impairment. J Alzheimers Dis 53, 1405-1410.

[211] Jiang S, Yan C, Qiao Z, Yao H, Jiang S, Qiu X, Yang X, Fang D, Yang Y, Zhang L, Wang L, Zhang L (2017) Mismatch negativity as a potential neurobiological marker of early-stage Alzheimer disease and vascular dementia. Neurosci Lett 647, 26-31.

[212] Jung MS, Kim H, Lee Y, Kim M, Chung E (2017) Different effects of cognitive and non-exercise physical leisure activities on cognitive function by age in elderly Korean individuals. Osong Public Heal Res Perspect 8, 308-317.

[213] Häggström J, Rosenhall U, Hederstierna C, Östberg P, Idrizbegovic E (2018) A longitudinal study of peripheral and central auditory function in Alzheimer's disease and in mild cognitive impairment. Dement Geriatr Cogn Dis Extra 8, 393-401. 
[214] Mamo SK, Nirmalasari O, Nieman CL, McNabney MK, Simpson A, Oh ES, Lin FR (2017) Hearing care intervention for persons with dementia: A pilot study. Am J Geriatr Psychiatry 25, 91-101.

[215] Grube M, Bruffaerts R, Schaeverbeke J, Neyens V, De Weer AS, Seghers A, Bergmans B, Dries E, Griffiths TD, Vandenberghe R (2016) Core auditory processing deficits in primary progressive aphasia. Brain 139, 1817-1829.

[216] Güntekin B, Hanoglu L, Güner D, Yilmaz NH, Çadirci F, Mantar N, Aktürk T, Emek-Savaş DD, Özer FF, Yener G, Basar E (2018) Cognitive impairment in Parkinson's disease is reflected with gradual decrease of EEG delta responses during auditory discrimination. Front Psychol 9, 170 .

[217] Bigelow RT, Semenov YR, Trevino C, Ferrucci L, Resnick SM, Simonsick EM, Xue QL, Agrawal Y (2015) Association between visuospatial ability and vestibular function in the Baltimore Longitudinal Study of Aging. J Am Geriatr Soc 63, 1837-1844.

[218] Bender S, Bluschke A, Dippel G, Rupp A, Weisbrod M, Thomas C (2014) Auditory post-processing in a passive listening task is deficient in Alzheimer's disease. Clin Neurophysiol 125, 53-62.

[219] Clark CN, Nicholas JM, Agustus JL, Hardy CJD, Russell LL, Brotherhood EV, Dick KM, Marshall CR, Mummery CJ, Rohrer JD, Warren JD (2017) Auditory conflict and congruence in frontotemporal dementia. Neuropsychologia 104, 144-156.

[220] Hardy CJD, Frost C, Sivasathiaseelan H, Johnson JCS, Agustus JL, Bond RL, Benhamou E, Russell LL, Marshall CR, Rohrer JD, Bamiou DE, Warren JD (2019) Findings of impaired hearing in patients with nonfluent/agrammatic variant primary progressive aphasia. JAMA Neurol 76, 607-611.

[221] Fisher DE, Li C-M, Hoffman HJ, Chiu MS, Themann CL, Petersen H, Jonsson P V., Jonsson H, Jonasson F, Sverrisdottir JE, Launer LJ, Eiriksdottir G, Gudnason V, Cotch MF (2015) Sex-specific predictors of hearing-aid use in older persons: The age, gene/environment susceptibility Reykjavik study. Int J Audiol 54, 634-641.

[222] Fischer ME, Cruickshanks KJ, Nondahl DM, Klein BEK, Klein R, Pankow JS, Tweed TS, Dalton DS, Paulsen AJ (2017) Dichotic digits test performance across the ages: Results from two large epidemiologic cohort studies. Ear Hear 38, 314-320.

[223] Gussekloo J, De Craen AJM, Oduber C, Van Boxtel MPJ, Westendorp RGJ (2005) Sensory impairment and cognitive functioning in oldest-old Subjects: The leiden 85+study. Am J Geriatr Psychiatry 13, 781-786.

[224] Hooper E, Simkin Z, Abrams H, Camacho E, Charalambous AP, Collin F, Constantinidou F, Dawes P, Elliott R, Falkingham S, Frison E, Hann M, Helmer C, Himmelsbach I, Hussain H, Marié S, Montecelo S, Reeves D, Regan J, Thodi C, Wolski L, Leroi I (2019) Feasibility of an intervention to support hearing and vision in dementia: The SENSE-Cog Field Trial. J Am Geriatr Soc 67, 1472-1477.

[225] Olsen R V., Hutchings BL, Ehrenkrantz E (2000) "Media Memory Lane" interventions in an Alzheimer's day care center. Am J Alzheimers Dis Other Demen 15, 163-175.

[226] Vallet GT, Hudon C, Simard M, Versace R (2013) The disconnection syndrome in the Alzheimer's disease: The cross-modal priming example. Cortex 49, 2402-2415.

[227] Krishnamurti S, Drake L, King J (2011) Neural network modeling of central auditory dysfunction in Alzheimer's disease. Neural Netw 24, 646-651.
[228] Omar R, Hailstone JC, Warren JE, Crutch SJ, Warren JD (2010) The cognitive organization of music knowledge: A clinical analysis. Brain 133, 1200-1213.

[229] Gates GA, Anderson ML, Feeney MP, McCurry SM, Larson EB (2008) Central auditory dysfunction in older persons with memory impairment or alzheimer dementia. Arch Otolaryngol Head Neck Surg 134, 771-777.

[230] Cancelli I, Cadore IP, Merlino G, Valentinis L, Moratti U, Bergonzi P, Gigli GL, Valente M (2006) Sensory gating deficit assessed by $\mathrm{P} 50 / \mathrm{Pb}$ middle latency event related potential in Alzheimer's disease. J Clin Neurophysiol 23, 421-425.

[231] Duchek JM, Balota DA (2005) Failure to control prepotent pathways in early stage dementia of the Alzheimer's type: Evidence from dichotic listening. Neuropsychology 19, 687-695.

[232] Wang NY, Su JF, Dong HQ, Jia JP, Han DM (2005) [Hearing impairment in patients with mild cognitive impairment and Alzheimer's disease]. Zhonghua Er Bi Yan Hou Tou Jing Wai Ke Za Zhi 40, 279-282.

[233] Cordone A, Bavazzano M, Sismondini A, Mora R, D'Angelo M, Cordone G, Salami A (1999) Mid-latency auditory evoked responses in Alzheimer's disease: Evaluation of P1 and P3 waves. Acta Otorhinolaryngol Ital 19, 64-69.

[234] Salazar R, Cerghet M, Ramachandran V (2014) Bilateral hearing loss heralding sporadic Creutzfeldt-Jakob disease: A case report and literature review. Otol Neurotol 35, 13271329.

[235] Sommers MS (1998) Spoken word recognition in individuals with dementia of the Alzheimer's type: Changes in talker normalization and lexical discrimination. Psychol Aging 13, 631-646.

[236] Gates GA, Cobb JL, Linn RT, Rees T, Wolf PA, D'Agostino RB (1996) Central auditory dysfunction, cognitive dysfunction, and dementia in older people. Arch Otolaryngol Head Neck Surg 122, 161-167.

[237] Pekkonen E, Huotilainen M, Virtanen J, Näätänen R, Ilmoniemi RJ, Erkinjuntti T (1996) Alzheimer's disease affects parallel processing between the auditory cortices. Neuroreport 7, 1365-1368.

[238] Holt LE, Raine A, Pa G, Schneider LS, Henderson VW, Pollock VE (1995) P300 topography in Alzheimer's disease. Psychophysiology 32, 257-265.

[239] Strouse A, Hall JW (1995) Test-retest reliability of a dichotic digits test for assessing central auditory function in Alzheimer's disease. Int J Audiol 34, 85-90.

[240] Golob EJ, Irimajiri R, Starr A (2007) Auditory cortical activity in amnestic mild cognitive impairment: Relationship to subtype and conversion to dementia. Brain 130, 740-752.

[241] Shiltz DL, Lineweaver TT, Brimmer T, Cairns AC, Halcomb DS, Juett J, Beer L, Hay DP, Plewes J (2018) “Music first" an alternative or adjunct to psychotropic medications for the behavioral and psychological symptoms of dementia. GeroPsych J Gerontopsychology Geriatr Psychiatry 31, 17-30.

[242] Mitoku K, Masaki N, Ogata Y, Okamoto K (2016) Vision and hearing impairments, cognitive impairment and mortality among long-term care recipients: A populationbased cohort study. BMC Geriatr 16, 112.

[243] Boyd M, Bowman C, Broad JB, Connolly MJ (2012) International comparison of long-term care resident dependency across four countries (1998-2009): A descriptive study. Australas J Ageing 31, 233-240. 
[244] Haque R, Abdelrehman N, Alavi Z (2012) "There's a monster under my bed": Hearing aids and dementia in long-term care settings. Ann Long-Term Care 20, 28-33.

[245] Pinheiro MMC, Iório MCM, Miranda EC, Dias KZ, Pereira LD (2012) The influence of cognitive aspects and auditory processes on the hearing aid acclimatization in the elderly. J Soc Bras Fonoaudiol 24, 309-315.

[246] Burkhalter CL, Allen RS, Skaar DC, Crittenden J, Burgio LD (2009) Examining the effectiveness of traditional audiological assessments for nursing home residents with dementia-related behaviors. J Am Acad Audiol 20, 529-538.

[247] Flatau E, Syndulko K, Flatau Y, Osterweil D (1998) Hearing impairment in residents of a long-term care facility: Prevalence and relationship to cognitive dysfunction. Ann Long Term Care 6, 410-413.

[248] Dong SH, Park JM, Kwon OE, Kim SH, Yeo SG (2019) The relationship between age-related hearing loss and cognitive disorder. ORL 81, 265-273.

[249] Jervis BW, Bigan C, Jervis MW, Besleaga M (2019) New-onset Alzheimer's disease and normal subjects $100 \%$ differentiated by P300. Am J Alzheimers Dis Other Demen 34, 308-313.

[250] Uchida Y, Nishita Y, Kato T, Iwata K, Sugiura S, Suzuki H, Sone M, Tange C, Otsuka R, Ando F, Shimokata H, Nakamura A (2018) Smaller hippocampal volume and degraded peripheral hearing among Japanese community dwellers. Front Aging Neurosci 10, 319.

[251] Golden HL, Clark CN, Nicholas JM, Cohen MH, Slattery CF, Paterson RW, Foulkes AJM, Schott JM, Mummery CJ, Crutch SJ, Warren JD (2017) Music perception in dementia. J Alzheimers Dis 55, 933-949.

[252] Kim SY, Kim HJ, Park EK, Joe J, Sim S, Choi HG (2017) Severe hearing impairment and risk of depression: A national cohort study. PLoS One 12, e0179973.

[253] Kurichi JE, Kwong PL, Xie D, Bogner HR (2017) Predictive indices for functional improvement and deterioration, institutionalization, and death among elderly Medicare beneficiaries. PM R 9, 1065-1076.

[254] Fletcher PD, Nicholas JM, Downey LE, Golden HL, Clark CN, Pires C, Agustus JL, Mummery CJ, Schott JM, Rohrer JD, Crutch SJ, Warren JD (2016) A physiological signature of sound meaning in dementia. Cortex 77, 13-23.

[255] Lodeiro-Fernández L, Lorenzo-López L, Maseda A, Núñez-Naveira L, Rodríguez-Villamil JL, Millán-Calenti J (2015) The impact of hearing loss on language performance in older adults with different stages of cognitive function. Clin Interv Aging 10, 695-702.

[256] Hailstone JC, Ridgway GR, Bartlett JW, Goll JC, Buckley AH, Crutch SJ, Warren JD (2011) Voice processing in dementia: A neuropsychological and neuroanatomical analysis. Brain 134, 2535-2547.

[257] Golden HL, Agustus JL, Nicholas JM, Schott JM, Crutch SJ, Mancini L, Warren JD (2016) Functional neuroanatomy of spatial sound processing in Alzheimer's disease. Neurobiol Aging 39, 154-164.

[258] Golden HL, Agustus JL, Goll JC, Downey LE, Mummery CJ, Schott JM, Crutch SJ, Warren JD (2015) Functional neuroanatomy of auditory scene analysis in Alzheimer's disease. Neuroimage Clin 7, 699-708.

[259] Golden HL, Downey LE, Fletcher PD, Mahoney CJ, Schott JM, Mummery CJ, Crutch SJ, Warren JD (2015) Identification of environmental sounds and melodies in syndromes of anterior temporal lobe degeneration. $\mathrm{J} \mathrm{Neu}$ rol Sci 352, 94-98.
[260] Golden HL, Nicholas JM, Yong KXX, Downey LE, Schott JM, Mummery CJ, Crutch SJ, Warren JD (2015) Auditory spatial processing in Alzheimer's disease. Brain 138, 189-202.

[261] Goll JC, Kim LG, Ridgway GR, Hailstone JC, Lehmann M, Buckley AH, Crutch SJ, Warren JD (2012) Impairments of auditory scene analysis in Alzheimer's disease. Brain 135, 190-200.

[262] Bouma A, Gootjes L (2011) Effects of attention on dichotic listening in elderly and patients with dementia of the Alzheimer type. Brain Cogn 76, 286-293.

[263] Goll JC, Crutch SJ, Loo JHY, Rohrer JD, Frost C, Bamiou DE, Warren JD (2010) Non-verbal sound processing in the primary progressive aphasias. Brain 133, 272-285.

[264] Lindenberger U, Ghisletta P (2009) Cognitive and sensory declines in old age: gauging the evidence for a common cause. Psychol Aging 24, 1-16.

[265] Knussen C, Tolson D, Brogan CA, Swan IRC, Stott DJ, Sullivan F (2008) Family caregivers of older relatives: Ways of coping and change in distress. Psychol Health Med 13, 274-290.

[266] Chung JCC (2006) Measuring sensory processing patterns of older Chinese people: Psychometric validation of the adult sensory profile. Aging Ment Health 10, 648-655.

[267] Idrizbegovic E, Hederstierna C, Dahlquist M, Nordström CK, Jelic V, Rosenhall U (2011) Central auditory function in early Alzheimer's disease and in mild cognitive impairment. Age Ageing 40, 249-254.

[268] Tarkka IM, Lehtovirta M, Soininen H, Paakkonen A, Karhu J, Partanen J (2002) Auditory adaptation is differentially impaired in familial and sporadic Alzheimer's disease. Biomed Pharmacother 56, 45-49.

[269] Moreaud O, David D, Charnallet A, Pellat J (2001) Are semantic errors actually semantic?: Evidence from Alzheimer's disease. Brain Lang 77, 176-186.

[270] Bayles KA, Tomoeda CK, Rein JA (1996) Phrase repetition in Alzheimer's disease: Effect of meaning and length. Brain Lang 54, 246-261.

[271] Claus JJ, Mohr E (1996) Attentional deficits in Alzheimer's, Parkinson's, and Huntington's diseases. Acta Neurol Scand 93, 346-351.

[272] Eustache F, Lambert J, Cassier C, Dary M, Rossa Y, Rioux P, Viader F, Lechevalier B (1995) Disorders of auditory identification in dementia of the Alzheimer type. Cortex 31, 119-127.

[273] Mataró M, Poca MA, Matarín M, Sahuquillo J, Sebastián N, Junqué C (2006) Corpus callosum functioning in patients with normal pressure hydrocephalus before and after surgery. J Neurol 253, 625-630.

[274] Kaf WA, Barboa LS, Fisher BJ, Snavely LA (2011) Effect of interdisciplinary service learning experience for audiology and speech-language pathology students working with adults with Dementia. Am J Audiol 20, 241-249.

[275] Reynolds T, Thornicroft G, Abas M, Woods B, Hoe J, Leese M, Orrell M (2000) Camberwell Assessment of Need for the Elderly (CANE). Development, validity and reliability. Br J Psychiatry 176, 444-452.

[276] Sandman PO, Adolfsson R, Norberg A, Nyström L, Winblad B (1988) Long-term care of the elderly. A descriptive study of 3600 institutionalized patients in the county of Västerbotten, Sweden. Compr Gerontol A 2, 120-132.

[277] Fries BE, Hawes C, Morris JN, Bernabei R (2006) Resident assessment instrument/minimum data set. In 
Principles and Practice of Geriatric Medicine, John Wiley \& Sons, Ltd, Chichester, UK, pp. 1855-1865.

[278] Schow RL, Nerbonne MA (1977) Assessment of hearing handicap by nursing home residents and staff. $J$ Acad Rehabil Audiol 10, 2-12.

[279] Ventry IM, Weinstein BE (1982) The hearing handicap inventory for the elderly: A new tool. Ear Hear 3, 128134.

[280] Gray LC, Berg K, Fries BE, Henrard JC, Hirdes JP, Steel K, Morris JN (2009) Sharing clinical information across care settings: The birth of an integrated assessment system. BMC Health Serv Res 9, 71.
[281] Littlejohn J, Bowen M, Constantinidou F, Dawes P, Dickinson C, Heyn P, Hooper E, Hopper T, Hubbard I, Langenbahn D, Nieman CL, Rajagopal M, Thodi C, Weinstein B, Wittich W, Leroi I (2021) International practice recommendations for the recognition and management of hearing and vision impairment in people with dementia. Gerontology, doi:10.1159/000515892.

[282] Wittich W, Jarry J, Höbler F, McGilton KS (2019) Agreement on the use of sensory screening techniques by nurses for older adults with cognitive impairment in long-term care: A mixed-methods consensus approach. BMJ Open 9, $\mathrm{e} 027803$. 